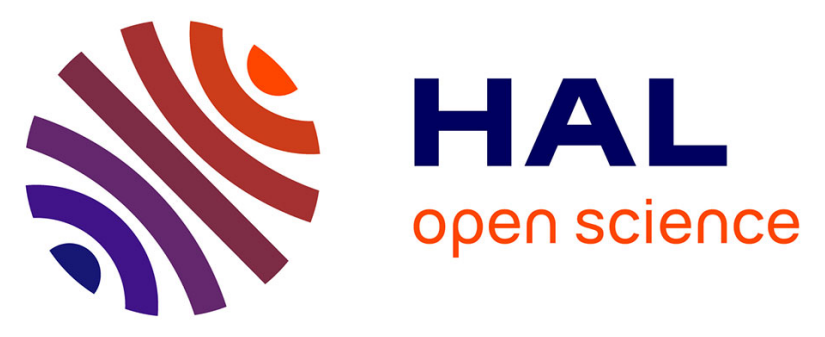

\title{
Synthesis, Characterization and Catalytic Studies of Chromium(III) Porphyrin Complex with axial cyanate ligands
}

Azhar Kechiche, Taissir Fradi, Olfa Noureddine, Mouhieddinne Guergueb, Frédérique Loiseau, Vincent Guerineau, Noureddine Issoui, Alla G. Bessmertnykh-Lemeune, Habib Nasri

\section{To cite this version:}

Azhar Kechiche, Taissir Fradi, Olfa Noureddine, Mouhieddinne Guergueb, Frédérique Loiseau, et al.. Synthesis, Characterization and Catalytic Studies of Chromium(III) Porphyrin Complex with axial cyanate ligands. Journal of Molecular Structure, In press, 10.1016/j.molstruc.2021.131801 . hal03414766

\author{
HAL Id: hal-03414766 \\ https://hal.science/hal-03414766
}

Submitted on 4 Nov 2021

HAL is a multi-disciplinary open access archive for the deposit and dissemination of scientific research documents, whether they are published or not. The documents may come from teaching and research institutions in France or abroad, or from public or private research centers.
L'archive ouverte pluridisciplinaire HAL, est destinée au dépôt et à la diffusion de documents scientifiques de niveau recherche, publiés ou non, émanant des établissements d'enseignement et de recherche français ou étrangers, des laboratoires publics ou privés. 


\title{
Synthesis, Characterization and Catalytic Studies of Chromium(III) Porphyrin Complex with axial cyanate ligands
}

\author{
Azhar Kechiche ${ }^{a}$, Taissir Fradi ${ }^{a}$, Olfa Noureddine ${ }^{b}$, Mouhieddinne Guergueb ${ }^{a}$, Frédérique \\ Loiseau ${ }^{c}$, Vincent Guerineau ${ }^{f}$, Noureddine Issoui ${ }^{b}$, Alla Lemeune ${ }^{d}$ Habib Nasri ${ }^{a}{ }^{*}$
}

${ }^{a}$ : University of Monastir, Laboratory of Physical Chemistry of Materials (LR01ES19), Faculty of Sciences of Monastir, Avenue de l'environnement, 5019 Monastir, Tunisia.

${ }^{b}$ : University of Monastir, Laboratory of Quantum and Statistical Physics LR18ES18, Faculty of Sciences of Monastir, Monastir, 5079, Tunisia.

${ }^{e}$ : Département de Chimie Moléculaire, 301 rue de la Chimie, Université Grenoble Alpes, CS 40700, 38058 Grenoble Cedex 9, France

${ }^{f}$ : Institut de Chimie des Substances Naturelles CNRS, Avenue de la Terrasse, F-91198 Gif-sur-Yvette, France.

${ }^{d}$ : Laboratoire de Chimie, Ecole Normale Superieure de Lyon (ENS), 46, Allée d'Italie, 69364 Lyon CEDEX 07, France

\begin{abstract}
We report the synthesis and the spectroscopic, structural and electrochemical characterization of a new chromium(III) coordination compound namely the bis(cyanato- $\mathrm{K} N)[$ mesotetratolylporphyrinato $]$ chromate(III) (cryptand-222)potassium dihydrate [K(crypt222)][Cr $\left.{ }^{\mathrm{III}}(\mathrm{TTP})(\mathrm{NCO})_{2}\right] \cdot 2 \mathrm{H}_{2} \mathrm{O}$ (complex I). This compound crystallizes in the orthorhombic crystal system with the non-centrosymmetric space group $\mathrm{C} 222{ }_{1}$. The chromium and the potassium atoms are located at special positions in a two-fold axis. The crystal lattice of complex $\mathbf{I}$ is stabilized by $\mathrm{O}-\mathrm{H}^{\cdots \cdots} \mathrm{O}, \mathrm{C}-\mathrm{H}^{\cdots \cdots} \mathrm{O}, \mathrm{C}-\mathrm{H}^{\cdots} \mathrm{N}$ and $\mathrm{C}-\mathrm{H}^{\cdots \cdots} \pi$ intermolecular contacts involving the negatively charged $\left[\mathrm{Cr}^{\mathrm{III}}(\mathrm{TTP})(\mathrm{NCO})_{2}\right]^{-}$species, the $\left[\mathrm{K}(\text { crypt-222) }]^{+}\right.$counterions and the two non-coordinated water molecules. Further insights on these weak intermolecular contacts are provided by the Hirshfeld surface analysis. Molecular electrostatic potential (MEP) theoretical calculation on [K(crypt222)][CrIII $\left.(\mathrm{TTP})(\mathrm{NCO})_{2}\right] \cdot 2 \mathrm{H}_{2} \mathrm{O}$ are reported. The new $\mathrm{Cr}(\mathrm{III})$ complex was efficient as a catalyst in the decomposition of Rhodamine $\mathrm{B}(\mathrm{RbH})$ dye by hydrogen peroxide. This coordination compound was also tested as photocatalyst of the photodecomposition of $\mathrm{RbH}$ dye by molecular oxygen.
\end{abstract}

\footnotetext{
* Corresponding author. Fax: +216 73500278.

E-mail address: hnasri1@gmail.com and habib.nasri@ fsm.rnu.tn (Habib Nasri).
} 
Keywords: chromium(III) porphyrin complex; X-ray molecular structure; Photophysical properties; Cyclic voltammetry; FMOs calculation analysis; Photodegradation.

\section{Introduction}

Metalloporphyrins have been extensively studied since the early 1960s. This great attention to the studies of these coordination compounds is mainly related to the fact that they were investigated as synthetic models for hemoproteins such as myoglobin, hemoglobin, cytochromes c and cytochromes P450. Among these models, $\mathrm{Fe}(\mathrm{III}), \mathrm{Mn}(\mathrm{III})$ and $\mathrm{Cr}$ (III) porphyrin coordination compounds with ground metal configurations $3 \mathrm{~d}^{5}, 3 \mathrm{~d}^{4}$ and $3 \mathrm{~d}^{3}$, respectively, show rather unusual electronic and optic proprieties. The mixing of metal and porphyrin orbitals leads to the appearance of a number of chargetransfer bands which alter classical electron absorption spectra of the porphyrin complexes in which only $\pi-\pi^{*}$ transitions of the macrocycle are observed [1]. Another interesting feature of porphyrin complexes with transition metals is an acceleration of the ligand exchange reactions which is closely related to their biological functions such as oxygen transport and storage and biocatalysis [2]. This effect is of particular interest for metal ions which is known to be inert in ligand exchange reactions such as $\mathrm{Co}(\mathrm{III}), \mathrm{Rh}(\mathrm{III})$ and $\mathrm{Cr}(\mathrm{III})$. For these reasons, $\mathrm{Cr}(\mathrm{III})$ porphyrins are widely studied and can find applications in particular in biomedicine [2].

The first published investigations on chromium(III) porphyrins date from the end of the sixties and the beginning of the seventies where we can quote those of Fleischer et al., La Mar et al., and Summerville et al. [3-6]. It is noteworthy that $\mathrm{Cr}(\mathrm{III})$ is the most stable oxidation state of chromium in porphyrin complexes but usual experimental procedures for the insertion of chromium in a porphyrin macrocycle consist of the reaction of free base porphyrins with anhydrous chromium(II) chloride and the reaction is carried out under inert atmosphere to yield the $\operatorname{Cr}(\mathrm{II})$ tetracoordinated species $\left[\mathrm{Cr}^{\mathrm{II}}(\mathrm{Porph})\right](\mathrm{Porph}=$ porphyrinate ligand). These complexes are unstable in air and spontaneously oxidized to yield pentacoordinated chlorido(porphyrin)chromium(III) complexes [Cr $\left.{ }^{\mathrm{III}}(\mathrm{Porph}) \mathrm{Cl}\right]$ which were widely investigated in solution and in solid state [6]. Notably, in all reported X-ray molecular structures $\mathrm{Cr}$ (III) porphyrin complexes chromium centers are hexacoordinated and up to date, only 31 structures are present in the Cambridge Structural Database (CSD Version 5.42, last update April 2021). In contrast, in the most metalloporphyrins bearing cyanate as an axial ligand, the metal centers adopt a square pyramidal geometry and this ditopic ligand occupies an axial position. Only two structures of metalloporphyrins bearing two cyanate ligands were reported, namely $\mathrm{Mn}$ (IV) 
and $\mathrm{Co}(\mathrm{III})$ complexes which are neutral and negatively charged species, respectively. Surprisingly, $\mathrm{Cr}(\mathrm{III})$ complexes with cyanate ligands were not reported so far.

Chromium(III) porphyrins have been widely investigated as catalysts and sensors. As example, the epoxidation of cis-polybutadiene using $\left[\mathrm{Cr}^{\mathrm{III}}(\mathrm{TPP}) \mathrm{Cl}\right](\mathrm{TPP}=$ meso-tetraphenylporphyrinate) as a catalyst [7]. More recently, it has been reported that the reaction between $\mathrm{CO}_{2}$ and propylene oxide catalyzed by $\left[\mathrm{Co}^{\mathrm{II}}(\mathrm{TPP}) \mathrm{Cl}\right]$ yields a mixture of poly(propylene carbonate) and a cyclic carbonate, while when $\left[\mathrm{Cr}^{\mathrm{III}}(\mathrm{TPP}) \mathrm{Cl}\right]$ is used as a catalyst, only the cyclic carbonate is synthesized [8]. Paolesse et al., [9] reported the use of $\left[\mathrm{Cr}^{\mathrm{III}}(\mathrm{TPP}) \mathrm{Cl}\left(\mathrm{H}_{2} \mathrm{O}\right)\right]$ immobilized into a mesoporous plasma-polymerised polydimethylsiloxane matrix in gaseous triethylamine sensing.

On the other hand, during the last decade, many porphyrins and metalloporphyrins were reported as catalysts for the degradation of organic dyes which is actual topic in environmental science. In this context, we published several papers on the use of zinc(II) and cobalt(II) metalloporphyrins in the degradation of methylene blue and malachite green [10-13]. Among organic dyes, the Rhodamine $\mathrm{B}(\mathrm{RhB})$ has magenta color in aqueous solution at $\mathrm{pH}=7$ due to strong light absorption $\left(\lambda_{\max }\right.$ value of $\sim 554 \mathrm{~nm}$ ). RhB dye is widely used as a colorant in industrial processes involving in paper, plastic, leather, food and cosmetic production which discharge-very large quantities

of this dye into seawater and rivers [14]. This xanthene dye is known to be carcinogen and can damage the nervous, reproductive and respiratory human being systems [15-17]. For all these raisons, a great number of investigations were devoted to the degradation of this dangerous organic dye.

In the present study, we describe the synthesis of the first $\mathrm{Cr}$ (III) porphyrin bearing the axial cyanate ligand. According to X-ray analysis, this is a rare example of metalloporphyrins bearing two axial cyanate ligands. The complex was also characterized in solution by UV-vis, fluorescence, IR and ${ }^{1} \mathrm{H}$ NMR spectroscopies and electrochemical studies. The Hirshfeld surfaces analysis and Frontier Molecular Orbitals (FMOs) were modelling using DFT calculations. Finally, newly synthesized "Cr(III)- bis(cyanate- $N$ )-complex I" was also studied as a catalyst in the photodecomposition of RhB and in the degradation of this dye by hydrogen peroxide.

\section{Experimental Section}

\section{1. Materials and methods}

UV-vis and IR spectroscopy: The electronic absorption spectra were recorded with a WinASPECT PLUS (validation for SPECORD PLUS version 4.2) scanning spectrophotometer. Solid IR spectra 
were obtained using a WinASPECTPLUS (validation for SPECORD PLUS version 4.2) scanning spectrophotometer.

MS spectrometry: Electrospray (ESI) spectra were carried out using an amaZon speed ion trap instrument and the ESI-HRMS spectra were recorded in an using LTQ Orbitrap XL apparatus (Thermo Scientific) equipped with an electrospray ionization (ESI) source. Solutions in dichloromethane were used for the analysis.

Emission spectroscopy: The emission spectra were recorded at room temperature with a Horiba Scientific Fluoromax-4 spectrofluorometer. The luminescence lifetime measurements were performed for excitation at $\lambda=450 \mathrm{~nm}$ using the second harmonic of a titanium-sapphire laser (picosecond Tsunami laser spectra physics 3950-M1BB and 39868- 03 pulse picker doubler) at an $800 \mathrm{kHz}$ repetition rate. Fluotime 200 from AMS technologies was used for the decay acquisition. It consists of a GaAs microchannel plate photomultiplier tube (Hamamatsu model R3809U-50) followed by a timecorrelated single photon counting system from Picoquant (PicoHarp300). The ultimate time resolution of the system is close to $30 \mathrm{ps}$. The luminescence decays were analyzed with the FLUOFIT software available from Picoquant. The mission quantum yields were determined at room temperature in dichloromethane solutions by using the optically dilute method [18]. [Zn(TPP)] in air-equilibrated dichloromethane solution was used as quantum yield standard $\left(\phi_{\mathrm{f}}=0.031\right)$ [19].

Electrochemistry: Cyclic voltammetry $(\mathrm{CV})$ experiments were performed with a $\mathrm{CH}-660 \mathrm{~B}$ potentiostat (CH Instruments). All analytical experiments were conducted at room temperature under an argon atmosphere (argon stream) in a standard one compartment, three-electrode electrochemical cell. Tetranbutylammonium perchlorate (TBAP) was used as a supporting electrolyte $(0.2 \mathrm{M})$ in dichloromethane previously distilled over calcium hydride under argon. An automatic ohmic drop compensation procedure was systematically implemented before the CV data were recorded with electrolytic solutions containing the studied compounds at concentrations of ca. $10^{-3} \mathrm{M}$. CH Instruments vitreous carbon $(\phi=$ $3 \mathrm{~mm}$ ) working electrodes were polished with $1 \mathrm{~mm}$ diamond paste before each recording. The $\mathrm{Ag} / \mathrm{AgNO}_{3}$ 0.01 $\mathrm{M}$ (TBAP 0.2 in $\mathrm{CH}_{2} \mathrm{Cl}_{2}$ ) redox couple was used as the reference electrode. The potential of the ferrocene/ferrocenium redox couple was used as an internal reference (86 $\mathrm{mV}$ vs. $\mathrm{Ag} / \mathrm{AgNO}_{3}$ under our experimental conditions). For comparison with previously published data, all potentials given in the text and in Table 6 have been converted to values relative to the saturated calomel electrode (SCE) according to the following relationship: $\mathrm{E}(\mathrm{SCE})=\mathrm{E}\left(\mathrm{Ag} / \mathrm{AgNO}_{3}\right)+298 \mathrm{mV}$. 
Hirshfeld surfaces (HSs) and 2D fingerprint plots (FPs) of complex I were obtained using the Crystal Explorer 3.15 software [20,22] based on the results of the single crystal X-ray diffraction studies. The $d_{\text {norm }}$ function can be described as the normalized contact distance and is based on both $d_{e}$ and $d_{i}$ and the van der Waals $(\mathrm{vdW})$ radii of the atom $[23,24]$ obtained by the following equation:

$$
d_{\text {norm }}=\frac{d_{i}-r_{i}^{v d W}}{r_{i}^{v d W}}+\frac{d_{e}-r_{e}^{v d W}}{r_{e}^{v d W}}
$$

Theoretical results were determined by GaussView [25] and Gaussian programs [26]. The molecular geometry structure of $\mathrm{X}$ molecule was optimised with the density functional theory (DFT) via the hybrid B3LYP (Becke's three parameter hybrid functional with Lee-Yang-Parr correlation functional LYP $[27,28]$ ) at LanL2DZ basis set. Molecular properties such as frontiers orbitals, gap energies and reactivity descriptors were computed using TD-DFT approach [28-31].

\subsection{Synthesis of [K(crypt-222)][Cr $\left.{ }^{I I I}(\mathrm{TTP})(\mathrm{NCO})_{2}\right] \cdot 2 \mathrm{H}_{2} \mathrm{O}(\mathrm{I})$.}

The meso-tetratolylporphyrin $\left(\mathrm{H}_{2} \mathrm{TTP}\right)$ was prepared by using the Alder and Longo method [32]. The chloride chromium(III) complex $\left[\mathrm{Cr}^{\mathrm{III}}(\mathrm{TTP}) \mathrm{Cl}\right]$ was prepared as reported in the literature [33]. Potassium cyanate $(50 \mathrm{mg}, 0.616 \mathrm{mmol})$ and cryptand $222(40 \mathrm{mg}, 0.106 \mathrm{mmol})$ were stirred together in dichloromethane $(30 \mathrm{~mL})$ at room temperature for $3 \mathrm{~h}$. Then a solution of $\left[\mathrm{Cr}^{\mathrm{III}}(\mathrm{TTP}) \mathrm{Cl}\right](40 \mathrm{mg}$, $0.056 \mathrm{mmol})$ in dichloromethane $(25 \mathrm{~mL})$ was added and the reaction mixture was stirred overnight. Complex I was precipitated from the reaction mixture by slow diffusion of $n$-hexanes. The dark green precipitate was filtered and dried in air (63 mg, 90\% yield) Elemental analysis calcd (\%) for

$\mathrm{C}_{68} \mathrm{H}_{72} \mathrm{CrKN}_{8} \mathrm{O}_{8} \cdot 2 \mathrm{H}_{2} \mathrm{O} \mathrm{C}$ 65.00, H 6.10, N 8.92; found: C 65.62, H 6.31, N 8.79; HRMS (ESI) (dichloromethane): $m / z$ [Cr $\left.{ }^{\mathrm{III}}(\mathrm{TTP})(\mathrm{NCO})_{2}\right]^{+}$calcd for $\mathrm{C}_{67} \mathrm{H}_{72} \mathrm{CrN}_{7} \mathrm{O}_{7}$ :-804.8740; found: 804.2298 ; MS (ESI) (dichloromethane): $m / z$ [K(crypt-222) $]^{+}$calcd for $\mathrm{C}_{18} \mathrm{H}_{36} \mathrm{KN}_{2} \mathrm{O}_{6}$ 415.22; found 415.11; UV-vis: $\lambda_{\max }(\mathrm{nm})$-in $\left.\mathrm{CHCl}_{3},(\log \varepsilon)\right] 404$ (4.24), 553 (5.14), 523(2.59), 584 (3.39), 619 (3.71) nm; FT-IR (solid neat): $\bar{v}\left(\mathrm{~cm}^{-1}\right)=2973-2819(\mathrm{CH}$ Porph $\left.)\right), 2973$ and 28732196 and 2149(sh) $\left(v\left(\mathrm{C} \equiv \mathrm{N} \mathrm{NCO}^{-}\right.\right.$ligand $\left.)\right)$, 1100 ( $v\left(-\mathrm{CH}_{2}-\mathrm{O}-\mathrm{CH}_{2}-\right)$, crypt-222), 1006 ( $\delta \mathrm{CCH}$ Porph).

\subsection{X-ray structure determination}

Single crystals of $\left[\mathrm{K}\left(\right.\right.$ crypt-222)][Cr $\left.{ }^{\mathrm{III}}(\mathrm{TTP})(\mathrm{NCO})_{2}\right] \cdot 2 \mathrm{H}_{2} \mathrm{O}$ (complex I) were obtained by slow diffusion of $n$-hexane into a dichloromethane solution of complex I. A suitable crystal of this complex was used for data collection in a Bruker-AXS-Enraf-Nonius Kappa APEXII diffractometer. The 
instrument was equipped with $\mathrm{CCD}$ area detector and data were collected using graphitemonochromated Mo K $\alpha$ radiation $(\lambda=0.71073 \AA$ ) at low temperature (200(2) K). The data were scaled and corrected for absorption correction using SADABS-2004/1 (Bruker, 2004) [34]. The structure was solved by direct methods by using SIR-2004 [35] and refined by full-matrix least-squares techniques on $\mathrm{F}^{2}$ by using the SHELXL-2014 program [36]. The $\mathrm{C}-\mathrm{O}$ group of the cyanate axial ligand is disordered in two positions (C29-O1 and C29A-O1A) with an occupancy factor of the major position of $0.738(0.028)$. The anisotropic displacement ellipsoids of the disordered atoms are very elongated, which indicate that they are statistically disordered. For these atoms, ISOR/SIMU restraints commands in the SHELXL-2014 software were used [37]. The H atoms were placed in calculated positions and treated as riding on their parent atoms except those of the water molecule (oxygen O5) where the correspondent hydrogens were located in the difference-Fourier map and refined isotropically. The geometrical calculations were carried out using the program PLATON [38]. The molecular and packing diagrams were generated using the software MERCURY [39]. The crystallographic data and structural refinement details of complex $\mathbf{I}$ is shown in Table 1. Selected bond lengths and angles for the compound are listed in Table 2.

Table 1. Crystal data and structural refinement for $\left[\mathrm{K}(\right.$ crypt-222) $]\left[\mathrm{Cr}^{\mathrm{III}}(\mathrm{TTP})(\mathrm{NCO})_{2}\right] \cdot 2 \mathrm{H}_{2} \mathrm{O}($ complex I).

$\begin{array}{lc}\text { Formula } & \mathrm{C}_{68} \mathrm{H}_{76} \mathrm{CrKN}_{8} \mathrm{O}_{10} \\ \text { M.W. } & 1256.46 \\ \text { Crystal System } & \text { orthorhombic } \\ \text { Crystal } & C 222_{1} \\ a(\AA) & 10.846(2) \\ b(\AA) & 21.982(4) \\ c(\AA) & 27.620(6) \\ V\left(\AA^{3}\right) & 6585(2) \\ Z & 4 \\ \rho_{\text {calc. }} / \mathrm{g} \mathrm{cm}^{-3} & 1.267 \\ \mu / \mathrm{mm}^{-1} & 0.300 \\ F(000) & 2652 \\ \text { Crystal size }\left(\mathrm{mm}^{3}\right) & 0.35 \times 0.24 \times 0.24 \\ \text { Crystal Color } & \text { purple } \\ \text { Crystal Shape } & \text { block } \\ \text { T(K) } & 200(2) \\ \theta_{\text {min }}-\theta_{\text {max }}\left({ }^{\circ}\right) & 2.368-25.000 \\ \text { Limiting indices } & -12 \leq \mathrm{h} \leq 12,-24 \leq \mathrm{k} \leq 26,-32 \leq 1 \leq 32 \\ R(\text { int }) & 0.0463 \\ \text { Unique data } & 5730\end{array}$




$\begin{array}{ll}\text { Observed data }\left[I_{o}>2 \sigma\left(F_{o}\right)\right] & 3199 \\ \text { Parameters/Rest } & 426 / 40 \\ S[\text { Goodness of fit] } & 1.081 \\ R_{1}{ }^{a}, w R_{2}^{b}\left[F_{o}>4 \sigma\left(F_{o}\right)\right] & R_{1}=0.0486, w R_{2}=0.1246 \\ w R_{2}^{b} \text { [all data] } & R_{1}=0.0559, w R_{2}=0.1287 \\ \text { Min./max. res. }\left(\mathrm{eA}^{-3}\right) & 0.442 /-0.262 \\ \text { CCDC } & 2085498\end{array}$

${ }^{\mathrm{a}}: R 1=\Sigma|| F_{\mathrm{O}}|-| F_{\mathrm{C}}|| / \Sigma\left|F_{\mathrm{O}}\right|^{\mathrm{b}}, w R_{2}=\left\{\Sigma\left[w\left(\left|F_{\mathrm{O}}\right|^{2}-\left|F_{\mathrm{C}}\right|^{2}\right)^{2}\right] / \Sigma\left[w\left(\left|F_{\mathrm{O}}\right|^{2}\right)^{2}\right]\right\}^{1 / 2}$.

Table 2. Selected bond lengths $(\AA)$ and angles $\left(^{\circ}\right)$ of complex $\mathbf{I}$.

Chromium coordination polyhedron

\begin{tabular}{llll} 
Cr-N1 & $2.045(4)$ & N1-Cr-N2 & $179.20(15)$ \\
Cr-N2 & $2.039(4)$ & N1-Cr-N3 & $91.28(16)$ \\
Cr-N3 & $2.019(4)$ & N2-Cr-N3 & $88.23(16)$ \\
\multicolumn{5}{c}{ cyanato- $N$ Axial ligand } \\
N3-Cr & $2.019(4)$ & C29A-O1A & $1.23(2)$ \\
N3-C29 & $1.148(7)$ & C29-N3-Cr & $155.2(5)$ \\
N3-C29A & $1.148(7)$ & O1-C29-N3 & $174.6(10)$ \\
C29-O1 & $1.234(9)$ & O1A-C29A-N3 & $152.4(19)$
\end{tabular}

Potassium coordination polyhedron

$\begin{array}{llll}\text { K1-O2 } & 2.846(4) & \text { O2-K1-O4 } & 97.75(11) \\ \text { K1-O3 } & 2.859(3) & \text { O2-K1-N4 } & 60.83(12) \\ \text { K1-O4 } & 2.869(3) & \text { O3-K1-O4 } & 101.01(11) \\ \text { K1-N4 } & 2.935(4) & \text { O3-K1-N4 } & 61.77(10) \\ \text { O2-K1-O3 } & 97.47(11) & \text { O4-K1-N4 } & 61.04(11)\end{array}$

Catalytic studies. Investigations of the catalytic degradation of Rhodamine $B(R h B)$ dye in the presence of $\left[\mathrm{K}(\right.$ crypt-222) $]\left[\mathrm{Cr}^{\mathrm{III}}(\mathrm{TTP})(\mathrm{NCO})_{2}\right] \cdot 2 \mathrm{H}_{2} \mathrm{O}$ (complex I) and $\left[\mathrm{Cr}^{\mathrm{III}}(\mathrm{TTP}) \mathrm{Cl}\right]$ complexes were carried out in air. $10 \mathrm{mg}$ of complex $\mathbf{I}$ or $\left[\mathrm{Cr}^{\mathrm{III}}(\mathrm{TTP}) \mathrm{Cl}\right](0.008$ and $0.013 \mathrm{mmol}$, respectively) were added to $50 \mathrm{~mL}$ of $\mathrm{RhB}$ aqueous solution $\left(20 \mathrm{mg} . \mathrm{L}^{-1}, 2.08 \mathrm{mmol}\right)$. In photodegradation experiments, the stirred suspension was irradiated by household white LED (30 W) lamp for $30 \mathrm{~min}$. In the discoloration by using hydrogen peroxide, $6 \mathrm{~mL}$ of $30 \% \mathrm{H}_{2} \mathrm{O}_{2}(1.7 \mathrm{mmol})$ were added, and the reaction mixture was stirred for $30 \mathrm{~min}$ at room temperature. The reactions were monitored by UV-vis 
spectroscopy with time interval of $5 \mathrm{~min}$. The decrease of intensity of the absorption band maximum at $555 \mathrm{~nm}$ was used to estimate the rate of $\mathrm{RhB}$ decolorization. The degradation yield $(R \%)$ was calculated by using the relationship: $R(\%)=\left(\frac{C_{o}-C_{t}}{C_{o}}\right) \cdot 100$, where $C_{t}$ and $C_{\mathrm{o}}$ are the concentrations at time $t$ and initial concentration, respectively.

\section{Results and Discussion}

\subsection{Synthesis}

The complex was obtained by treatment of $\left[\mathrm{Cr}^{\mathrm{III}}(\mathrm{TTP}) \mathrm{Cl}\right]$ with an excess of potassium cyanate in the presence of cryptand-222 in dichloromethane in air. The axial ligand exchange smoothly proceeded at room temperature and the target complex was isolated in $90 \%$ yield using a slow diffusion of $n$-hexane in the reaction mixture followed by a filtration of precipitate thus obtained. According to elemental analysis the complex $\left[\mathrm{K}\left(\right.\right.$ crypt-222)][Cr $\left.\mathrm{Cr}^{\mathrm{III}}(\mathrm{TTP})(\mathrm{NCO})_{2}\right]$ was isolated as a dihydrate.

\subsection{ESI mass studies}

The ESI-HRMS mass spectrum depicted in Figure 1 confirms that two cyanate ligands are present in the coordination environment of chromium atom and complex $\mathbf{I}$ is hexacoordinated in dichloromethane solution. The experimental and the theoretical $\mathrm{m} / \mathrm{z}$ values of the fragment $\left[\mathrm{Cr}^{\mathrm{III}}(\mathrm{TTP})(\mathrm{NCO})_{2}\right]^{-}$are 804.2298 and 804.8740, respectively. The ESI-MS in positive ion mode confirms the presence of the $\left[\mathrm{K}(\text { crypt-222) }]^{+}\right.$counterion (theoretical value of $\mathrm{m} / \mathrm{z}$ is 415.22 ) by the presence of peak at a $\mathrm{m} / \mathrm{z} 415.11$

(Figure S1).

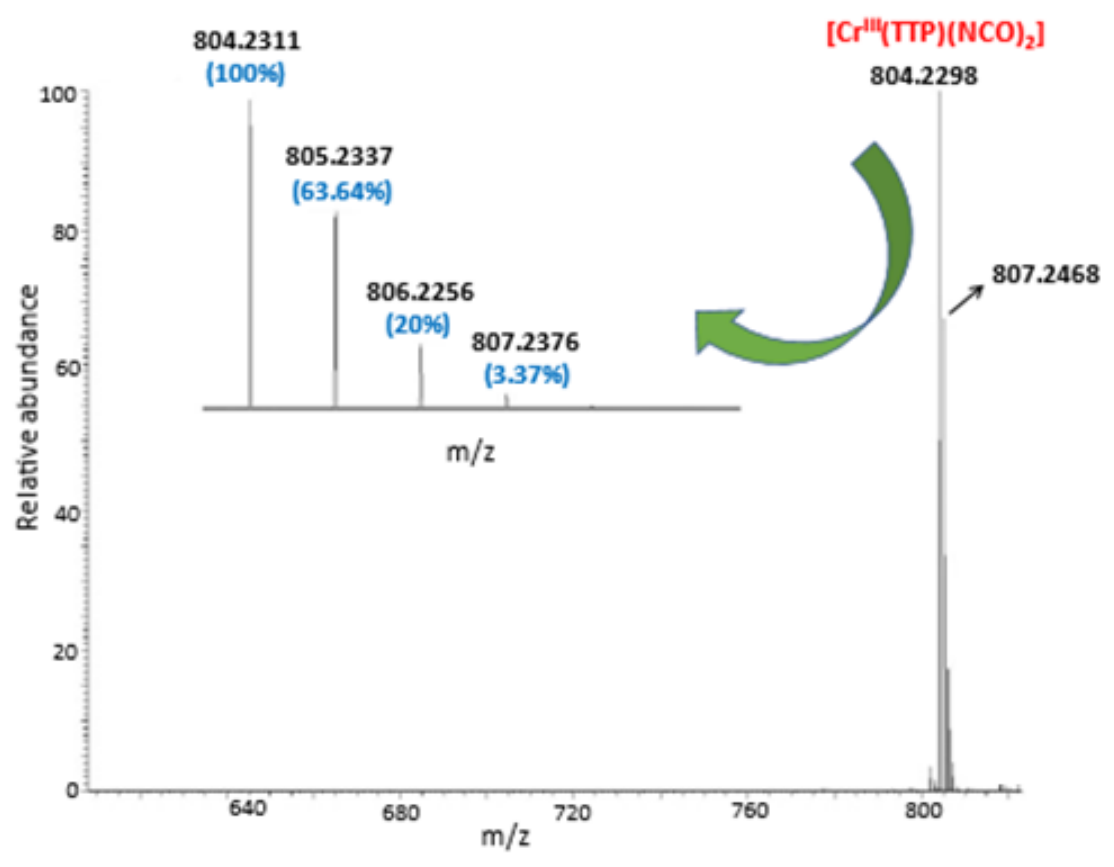


Figure 1. ESI-HRMS spectrum of complex I showing the isotopic ratio. The solvent used is the dichloromethane with a concentration of $5 \cdot 10^{-3} \mathrm{M}$ diluted to $5 \cdot 10^{-5} \mathrm{M}$.

\subsection{IR data of [K(crypt-222)][Cr $\left.{ }^{I I I}(\mathrm{TTP})(\mathrm{NCO})_{2}\right] \cdot 2 \mathrm{H}_{2} \mathrm{O}($ complex I)}

The IR spectrum of complex I exhibits typical absorption bands of the porphyrin macrocycle which are (i) a multiple bands between 2973 and $2819 \mathrm{~cm}^{-1}$ corresponding to the $\mathrm{C}-\mathrm{H}$ stretching vibrations which are overlapped with $\mathrm{C}-\mathrm{H}$ stretching vibrations of the cryptand, (ii) absorption bands in 1550$1500 \mathrm{~cm}^{-1}$ region in which both absorption of tetrapyrrolic macrocycle and phenyl groups are observed, (iii) a strong absorption band at $1009 \mathrm{~cm}^{-1}$ ascribed to the $\delta(\mathrm{CCH})$ vibration mode of the pyrrole fragments, and (iv) an absorption band with medium intensity at $760 \mathrm{~cm}^{-1}$ attributed to vibrations of pyrrole fragments. The presence of the $\left[\mathrm{K}(\text { cryp-222) }]^{+}\right.$counterion is confirmed by an intensive absorption band at $1100 \mathrm{~cm}^{-1}$ corresponded to the asymmetric stretching vibrations of $\mathrm{C}-\mathrm{O}-$ C groups. Intensive bands with the maxima at 2198 and $2149 \mathrm{~cm}^{-1}$ are attributed to the asymmetric stretching vibrations of the cyanate ligand (Figure 2). Notably, the value for $v_{\text {as }}$ for complex $\mathbf{I}$ is larger than that for the free $\mathrm{NCO}^{-}$ion $\left(\mathrm{NaNCO}: 2155 \mathrm{~cm}^{-1}\right)$ that can be regarded as an indication of its strong binding to $\mathrm{Cr}$ (III) ion. However, it is not clear from the IR data whether the cyanate axial ligand is $\kappa N$-bonded or $\kappa O$-bonded to the chromium(III) center.

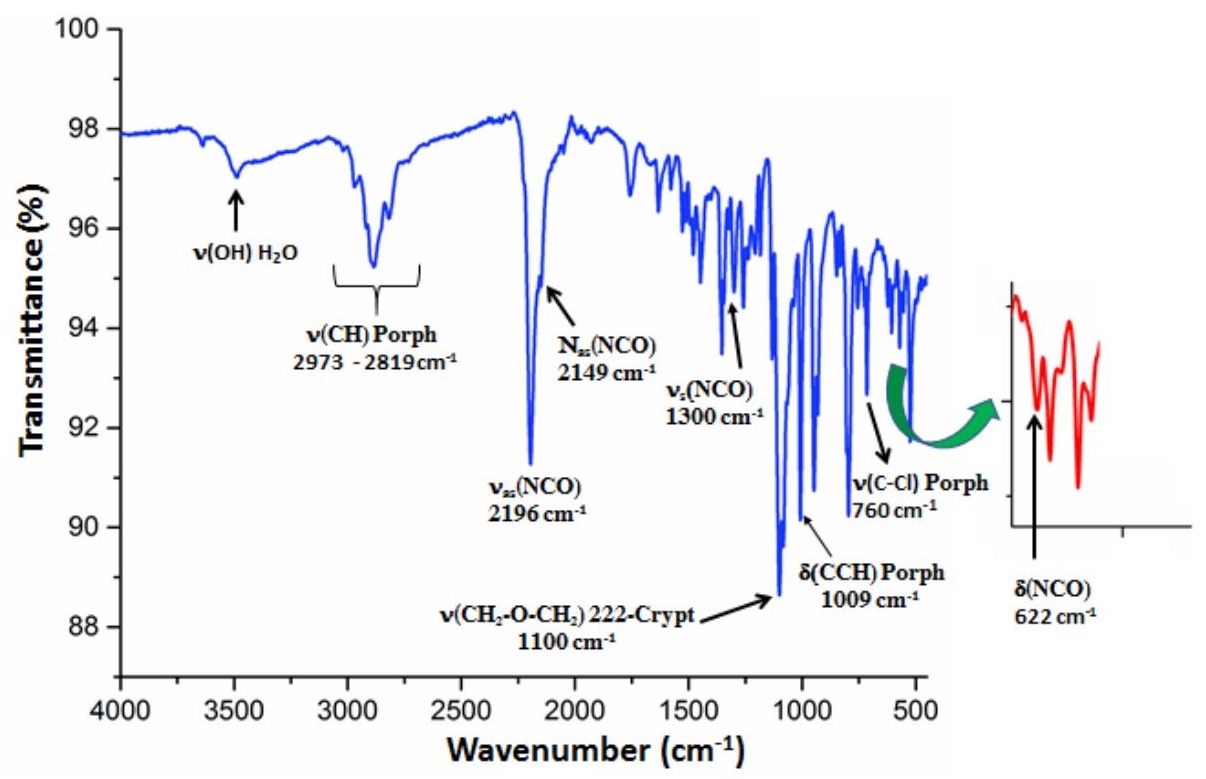




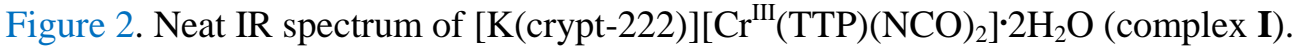

\subsection{Photophysical properties}

It is known that metalloporphyrins exhibit three types of UV-vis spectra known as normal, hypso and hyper types [40]. Normal light absorption spectra are well explained by Gouterman's four orbital model [41]. The hypso UV-vis spectra of metalloporphyrins look very much like the normal spectra, except that the $\mathrm{Q}$ bands are blue shifted (with $\lambda_{\max }<570 \mathrm{~nm}$ ). This type of spectra is found for transition metal complexes with metal electron configurations from $\mathrm{nd}^{6}$ to $\mathrm{nd}^{9}$. In contrast, the hyper spectra p-type and d-type show additional absorbance bands compared to porphyrin possessing the normal- and the hypso- type absorption spectra. These additional bands are satellite bands of moderate intensities. Main group elements in low oxidation states, such as $\mathrm{Sn}(\mathrm{II}), \mathrm{Pb}(\mathrm{II})$ and $\mathrm{As}(\mathrm{III})$ give $p$-type hyper spectra for which the extra bands are due to metal to ligand charge transfer (MLCT) [42]. Porphyrin complexes that exhibit $d$-type hyper absorption spectra are found with $\mathrm{d}^{1}$ through $\mathrm{d}^{6}$ metals that have vacancies in the $e_{g}\left(\mathrm{~d}_{\pi}\right)$ orbitals. These vacancies make a porphyrinic ring ligand to metal charge transfer (LMCT) possible. There is also considerable mixing of the $\mathrm{d} \pi$ orbitals with the LUMO orbital of the porphyrin, since they are of the same symmetry $\left(e_{\mathrm{g}}\right)$ [43]. This extensive orbital mixing accounts for the complex spectra often observed in d-type hyper metalloporphyrins. Calculations have shown [44] that $\mathrm{Cr}(\mathrm{III}), \mathrm{Mn}(\mathrm{III})$ and $\mathrm{Fe}(\mathrm{III})$ orbitals are uniquely situated in energy for extensive mixing to occur (Figure 3). An example of a UV-vis spectrum of a chromium(III) complex with a meso-tetraarylporphyrin is that of the $\left[\mathrm{Cr}^{\mathrm{III}}(\mathrm{TTP}) \mathrm{Cl}\right]$ complex shown in Figure $\mathrm{S} 2$. In the Soret region, this spectrum presents a major Soret band strongly-redshifted to $453 \mathrm{~nm}$ and a minor band with a maximum at $400 \mathrm{~nm}$ which is a LMCT band. Several LMCT bands with low intensities are also observed in the UV region of the spectrum. Three Q bands appear at 524, 567 and $606 \mathrm{~nm}$ and two LMCT weak absorption bands are present between 670 and $770 \mathrm{~nm}$ [43]. 
The electronic spectrum the negatively charged complex $\left[\mathrm{Cr}^{\mathrm{III}}(\mathrm{TTP})(\mathrm{OCN})_{2}\right]^{-}$is shown in Figure 4 while the UV-vis data of this complex and a selection of related $\mathrm{Cr}$ (III) and $\mathrm{Cr}$ (II) mesotetraarylporphyrins are summarized in Table 3.

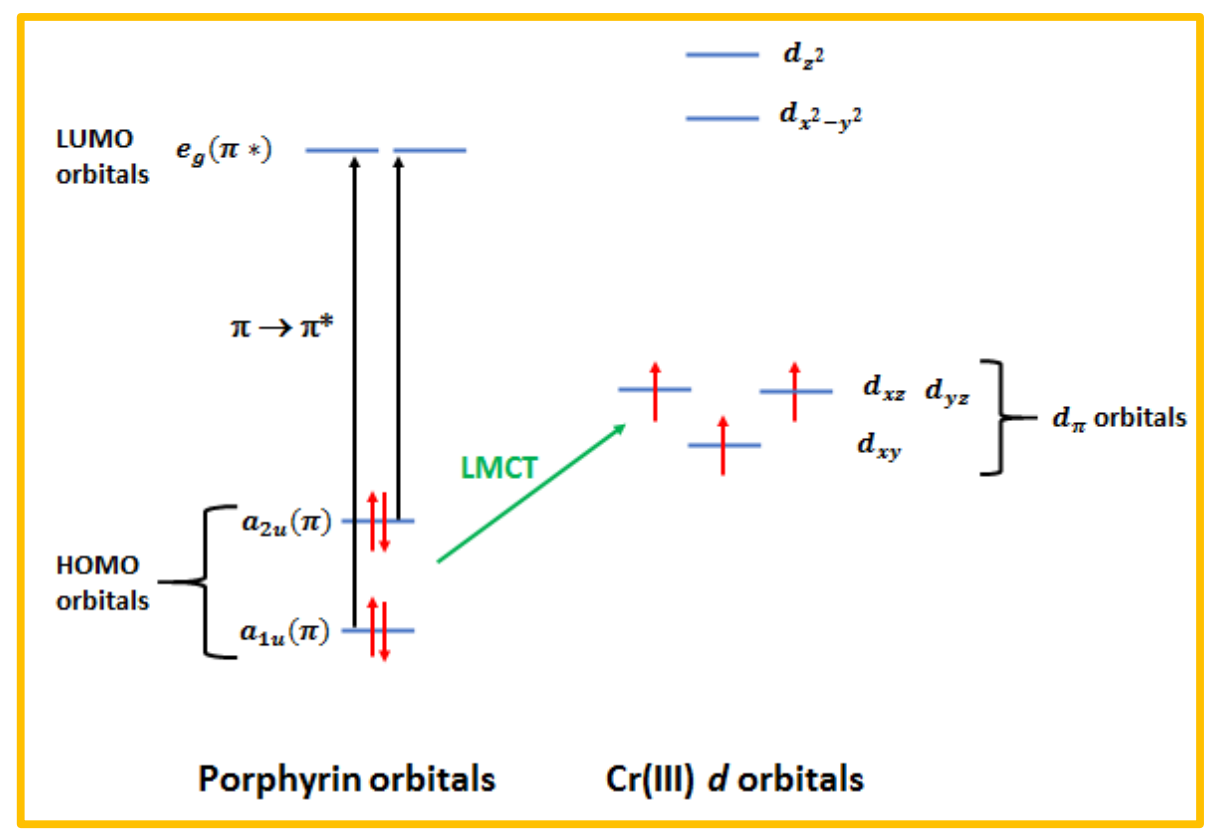

Figure 3. Schematic representation of energy levels of HOMO-LUMO porphyrin molecular orbitals and d orbitals of the chromium(III) center of $\left[\mathrm{Cr}^{\mathrm{III}}(\mathrm{TPP}) \mathrm{Cl}\right]$ complex [42]. 
Table 3. UV-vis data for complex I and a selection of related chromium(III) and chromium(II) metalloporphyrins.

\begin{tabular}{|c|c|c|c|c|}
\hline \multirow[t]{2}{*}{ Compound } & \multirow[t]{2}{*}{ Solvent } & Bands in the Soret region & Bands in the $\mathrm{Q}$ region & \multirow[t]{2}{*}{ Ref. } \\
\hline & & $\lambda_{\max }(\mathrm{nm})(\log \varepsilon)$ & & \\
\hline
\end{tabular}

Chromium(III) meso-arylporphyrin complexes

$\left[\mathrm{Cr}^{\mathrm{III}}(\mathrm{TPP}) \mathrm{Cl}\right]^{\mathrm{a}}$
$\left[\mathrm{Cr}^{\mathrm{III}}(\mathrm{TTP}) \mathrm{Cl}\right]$
$\left[\mathrm{Cr}{ }^{\mathrm{III}}(\mathrm{TPP}) \mathrm{Cl}(\mathrm{py})\right]^{\mathrm{a}}$
$\left[\mathrm{Cr} \mathrm{III}^{\mathrm{III}}(\mathrm{TPP}) \mathrm{Cl}(4-\mathrm{CNpy})\right]^{\mathrm{a}, \mathrm{b}}$
$\left[\mathrm{Cr}^{\mathrm{III}}(\mathrm{TPP}) \mathrm{Cl}(1-\mathrm{MeIm})\right]^{\mathrm{a}, \mathrm{c}}$
$\left[\mathrm{Cr}^{\mathrm{III}}(\mathrm{TPP})(\mathrm{OAc})\right]^{\mathrm{a}, \mathrm{d}}$
$\left[\mathrm{Cr}^{\mathrm{III}}(\mathrm{TTP})(\mathrm{NCO})_{2}\right]^{-}(\mathbf{I})$

$\begin{array}{lllllll}\mathrm{CH}_{2} \mathrm{Cl}_{2} & 398(4.59) & \mathbf{4 5 0}(5.37) & 528(3.66) & 565(4.01) & 604(3.94) & {[45]} \\ \mathrm{Toluene} & 401(4.42) & \mathbf{4 5 3}(5.11) & 522(3.76) & 570(3.89) & 611(3.98) & \text { this work } \\ \mathrm{CHCl}_{3} & 400(4 / 44) & \mathbf{4 5 2}(5.15) & 525(3.75) & 566(3.95) & 605(3.90 & \text { this work } \\ \mathrm{CH}_{2} \mathrm{Cl}_{2} & 370(4.39) & \mathbf{4 5 9}(5.20) & 530(3.66) & 573(3.97) & 613(4.06) & {[45]} \\ \mathrm{CH}_{2} \mathrm{Cl}_{2} & 404(4.45) & \mathbf{4 5 5}(4.89) & 530(3.63) & 575(3.93) & 615(4.00) & {[45]} \\ \mathrm{CH}_{2} \mathrm{Cl}_{2} & 404(4.63) & \mathbf{4 5 6}(5.36) & 532(3.62) & 574(3.93) & 615(4.00) & {[45]} \\ \mathrm{CHCl}_{3} & 396(4.34) & \mathbf{4 5 0}(5.20) & 523(3.65) & 565(3.99) & 605(3.90) & {[46]} \\ \mathrm{CHCl}_{3} & 404(4.24) & \mathbf{4 5 3}(5.14) & 532(2.59) & 584(3.39) & 619(3.71) & \text { this work }\end{array}$

Chromium(II) meso-arylporphyrin complexes

\begin{tabular}{lllllllll}
{$\left[\mathrm{Cr}^{\mathrm{II}}(\mathrm{TPP})\right]^{\mathrm{a}}$} & THF & 402 & $\mathbf{4 2 1}$ & 460 & 516 & 601 & 655 & {$[47]$} \\
{$\left[\mathrm{Cr}^{\mathrm{III}}(\mathrm{TPP})(4-\mathrm{pic})_{2}\right]^{\mathrm{a}, \mathrm{e}}$} & Toluene & 400 & $\mathbf{4 2 2}$ & - & 541 & - & 672 & {$[47]$} \\
{$[\mathrm{Cr}$} & Toluene & - & $\mathbf{4 2 0}$ & 455 & 530 & 610 & 675 & {$[47]$} \\
{$\left[\mathrm{Cr}{ }^{\mathrm{III}}(\mathrm{TPP})(\mathrm{TPy}){ }_{2}\right]$} & THF & 404 & $\mathbf{4 2 3}$ & 453 & 532 & 620 & 682 & {$[47]$} \\
\hline
\end{tabular}

${ }^{\mathrm{b}}: \mathrm{H}_{2} \mathrm{TPP}=$ meso-tetraphenylporphyrin, ${ }^{\mathrm{b}}:$ 4-CNpy $=4$-cyanopyridine, ${ }^{\mathrm{c}}: 1$-MeIm $=1$-methylimidazole, ${ }^{\mathrm{d}}:$ OAc $=$ acetate, ${ }^{\mathrm{e}}:$ 4-pic $=4$-picoline. 


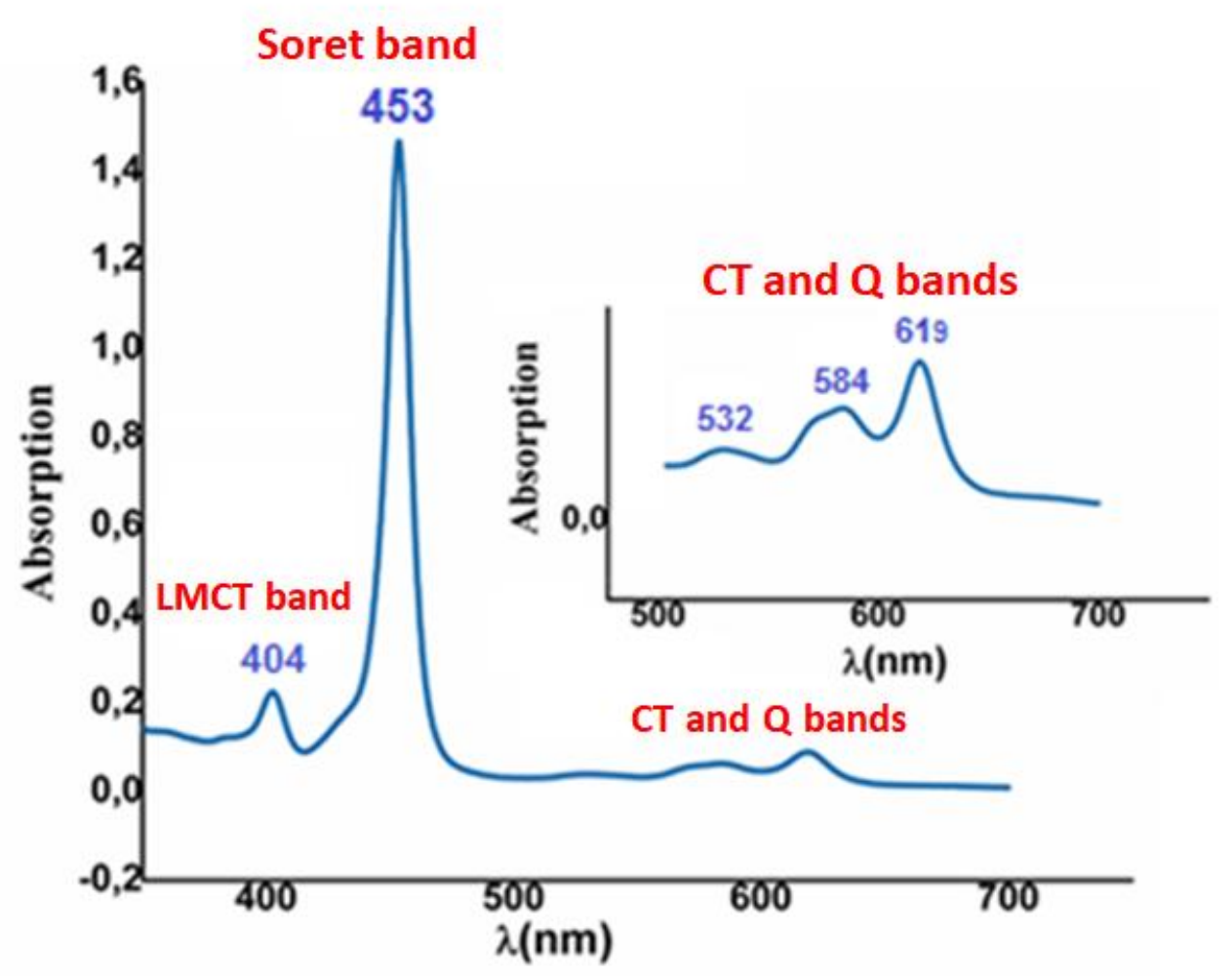

Figure 4. UV-vis-spectrum of complex I recorded in dichloromethane solution at concentration of $\sim 10^{-5} \mathrm{M}$.

The comparison of the UV-vis spectra of complex I (Figure 4) and the starting material $\left[\mathrm{Cr}^{\mathrm{III}}(\mathrm{TTP}) \mathrm{Cl}\right]$ (Figure S2) shows that (i) the low-intensity band (LMCT band) in Soret region observed at $404 \mathrm{~nm}$ is slightly red-shifted compared to that of the chloride chromium(III) derivative $(400 \mathrm{~nm})$, (ii) the $\lambda_{\max }$ values of the Soret bands of the chloride and bis $($ cyanate- $\kappa N)$ complexes are the same (453 nm) and (iii) the absorption bands in the $\mathrm{Q}$ region are red shifted compared to those of the $\left[\mathrm{Cr}^{\mathrm{III}}(\mathrm{TTP}) \mathrm{Cl}\right]$ with values of 526, 567 and $606 \mathrm{~nm}$ for $\left[\mathrm{Cr}^{\mathrm{III}}(\mathrm{TTP}) \mathrm{Cl}\right]$ and 532, 584 and $619 \mathrm{~nm}$ for $\left[\mathrm{Cr}^{\mathrm{III}}(\mathrm{TTP})(\mathrm{NCO})_{2}\right]^{-}$. One can notice from Table 3 that the pentacoordinated chromium(III) metalloporphyrins belonging to $\left[\mathrm{Cr}^{\mathrm{III}}(\mathrm{Porph}) \mathrm{X}\right]$ series, where Porph is a meso-tetraarylporphyrin and is $\mathrm{X}$ is an anionic ligand such as $\mathrm{Cl}^{-}$or OAc ${ }^{-}$exhibit similar UV-vis spectra with $\lambda_{\max }$ values of the Q bands at $\sim 526, \sim 567$ and $\sim 606 \mathrm{~nm}$. The absorbance bands of hexacoordinated $\mathrm{Cr}(\mathrm{III})$ metalloporphyrins $\left[\mathrm{Cr}^{\mathrm{III}}(\mathrm{Porph}) \mathrm{Cl}(\mathrm{L})\right]$ bearing a neutral $N$-donor axial ligand $\mathrm{L}$ such as pyridine or 1-methylimidazole are red-shifted $(\sim 530, \sim 573$ and $615 \mathrm{~nm}$ ) in this region as compared to those of pentacoordinated neutral $\mathrm{Cr}$ (III) metalloporphyrins $\left[\mathrm{Cr}^{\mathrm{III}}(\right.$ Porph $\left.) \mathrm{X}\right]$. For our negatively charged hexacoordinated complex $\left[\mathrm{Cr}^{\mathrm{III}}(\mathrm{TPP})(\mathrm{NCO})_{2}\right]^{-}$, these $\lambda_{\max }$ values are further shifted to longer wavelength. This probably can be explained by the negative charge 
of this complex [48]. Figure S3 represents the experimental variation of $(\alpha h v)^{2}$ versus the photo energy $(\mathrm{E}=h v)$ of $\left[\mathrm{Cr}^{\mathrm{III}}(\mathrm{TTP}) \mathrm{Cl}\right]$ and $\left[\mathrm{Cr}^{\mathrm{III}}(\mathrm{TTP})(\mathrm{NCO})_{2}\right]^{-}$complexes (where $\alpha$ is absorption coefficient, $h$ is the Planck constant and $v$ is the frequency $(v=1 / \lambda)$ ). The experimental optical gap (Eg-op) is determined from this plot using the Tauc plot method [49]. The experimental Eg-opt values of the chloridoporphyrinatochromium(III) and complex I (1.973 and $1.967 \mathrm{eV}$, respectively), indicates the semi-conductor character of these two Cr(III) metalloporphyrins.

Fluorescence spectra of $\mathrm{H}_{2}$ TTP free base porphyrin, $\left.\left[\mathrm{Cr}^{\mathrm{III}}(\mathrm{TTP}) \mathrm{Cl}\right)\right]$ and complex $\mathbf{I}$ are shown in Figure 5. Emission band maxima $\left(\lambda_{\max }\right)$, fluorescence quantum yields $\left(\Phi_{\mathrm{f}}\right)$ and lifetime $\left(\tau_{\mathrm{f}}\right)$ values are reported in Table 4 and a fluorescence decay curve of complex $\mathbf{I}$ is shown in Figure S4. The strongest emission bands of the porphyrins correspond to $S_{1} \rightarrow S_{0}$ transitions between the first singlet $S_{1}$ and the singlet ground $\mathrm{S}_{0}$ states. For all studied porphyrins, the $\mathrm{Q}(0,0)$ and $\mathrm{Q}(0,1)$ emission bands appear at 650 and $\sim 715 \mathrm{~nm}$. The fluorescence quantum yield $\left(\Phi_{\mathrm{f}}\right)$ decreases from $\sim 10 \%$ observed for the free base porphyrin $\mathrm{H}_{2}$ TTP to $\sim 5 \%$ and $\sim 2 \%$ in $\mathrm{Cr}$ (III) complexes bearing chloride and cyanate- $\kappa N$ ligand, respectively. The lifetime of exited state $\left(\tau_{\mathrm{f}}\right)$ also decreases in the same order being equal to 8.9, 5.4 and $2.1 \mathrm{~ns}$, respectively. It is noteworthy that emission properties of $\mathrm{Cr}(\mathrm{III})$ porphyrins are very close to those of the paramagnetic cobalt(II) metalloporphyrins (Table 4). As reported by Darwent et al., [50] the low fluorescence quantum yields and relatively short lifetimes of cobalt(II) and chromium(III) porphyrins can be explained by the paramagnetic nature of these species that allow for triple excited state intersystem crossing leading to the decrease of the $\Phi_{\mathrm{f}}$ and $\tau_{\mathrm{f}}$ values.

Table 4. Emission data for $\mathrm{H}_{2} \mathrm{TTP}$, [Cr ${ }^{\mathrm{III}}(\mathrm{TTP})(\mathrm{Cl}]$, $\left[\mathrm{K}\left(\right.\right.$ crypt-222)] $\left[\mathrm{Cr}^{\mathrm{III}}(\mathrm{TTP})(\mathrm{NCO})_{2}\right] \cdot 2 \mathrm{H}_{2} \mathrm{O}($ complex I) and a selection of meso-tetraarylporphyrins and cobalt(II) porphyrins.

\begin{tabular}{|c|c|c|c|c|}
\hline \multirow[t]{2}{*}{ Compound } & \multicolumn{2}{|c|}{$\lambda_{\max }(\mathrm{nm})$} & \multirow[t]{2}{*}{$\Phi_{\mathrm{f}}$} & \multirow[t]{2}{*}{$\tau_{\mathrm{f}}(\mathrm{ns})$} \\
\hline & $\mathrm{Q}(0,0)$ & $\mathrm{Q}(0,1)$ & & \\
\hline
\end{tabular}

Meso-arylporphyrins

\begin{tabular}{|c|c|c|c|c|c|}
\hline $\mathrm{H}_{2} \mathrm{TTP}$ & 655 & 719 & 0.10 & 8.9 & t.w. \\
\hline $\mathrm{H}_{2} \mathrm{TPP}$ & 653 & 722 & 0.12 & 9.6 & {$[51]$} \\
\hline $\mathrm{H}_{2} \mathrm{TPBP}^{\mathrm{a}}$ & 653 & 715 & 0.04 & 8.2 & {$[52]$} \\
\hline \multicolumn{6}{|c|}{ Cobalt(II) meso-arylporphyrin complexes } \\
\hline$\left[\mathrm{Co}^{\mathrm{II}}(\mathrm{TMPP})(4-\mathrm{CNpy})\right]^{\mathrm{b}, \mathrm{c}}$ & 652 & 717 & 0.054 & 1.97 & {$[53$} \\
\hline
\end{tabular}




\begin{tabular}{|c|c|c|c|c|c|}
\hline$\left[\mathrm{Co}^{\mathrm{II}}(\mathrm{TClPP})(4-\mathrm{CNpy})\right]^{\mathrm{d}, \mathrm{c}}$ & 653 & 714 & 0.060 & 1.99 & [53] \\
\hline$\left[\mathrm{Co}^{\mathrm{II}}(\mathrm{TPBP})\left(4,4^{\prime} \text {-bipy }\right)_{2}\right]^{\mathrm{a}, \mathrm{c}}$ & 652 & 718 & 0.036 & - & [54] \\
\hline
\end{tabular}

Chromium(III) meso-arylporphyrin complexes

$\begin{array}{llllll}{\left[\mathrm{Cr}^{\mathrm{III}}(\mathrm{TTP}) \mathrm{Cl}\right]} & 651 & 715 & 0.05 & 5.4 & \text { t.w. } \\ {\left[\mathrm{Cr}^{\mathrm{III}}(\mathrm{TTP})(\mathrm{NCO})_{2}\right]^{-}} & 650 & 714 & 0.02 & 2.1 & \text { t.w. }\end{array}$

${ }^{\mathrm{a}}:$ TPBP $=$ meso-tetrakis[4-(benzoyloxy)phenyl]porphinate, ${ }^{\mathrm{b}}:$ TMPP = meso-tetra(4-methoxyphenyl)porphyrinate, ${ }^{c}:$ 4-CNpy $=4$-cyanopyridine, ${ }^{\mathrm{d}}: \mathrm{TClPP}=$ meso-tetra(4-chlorophenyl)porphyrinate.

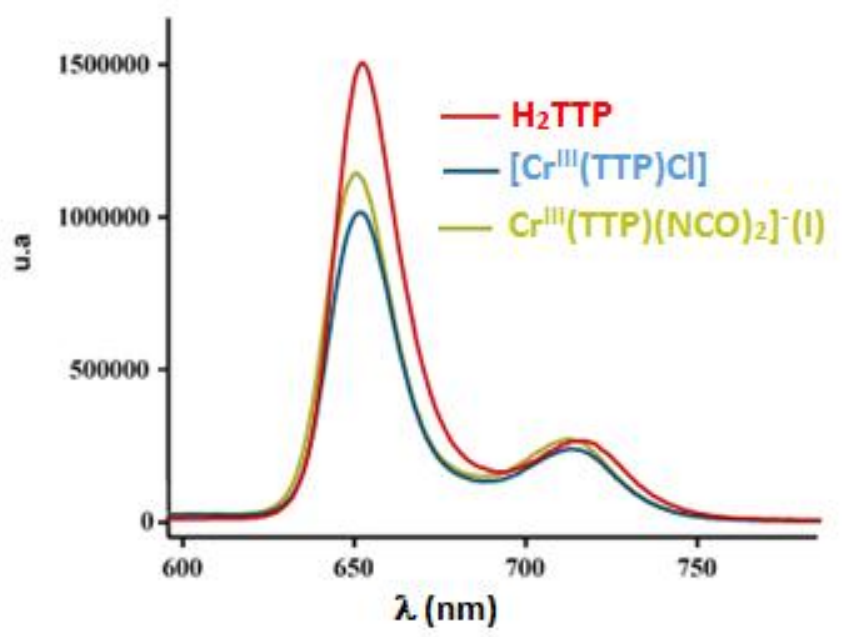

Figure 5. Room temperature emission spectra of $\mathrm{H}_{2} \mathrm{TTP},\left[\mathrm{Cr}^{\mathrm{III}}(\mathrm{TTP}) \mathrm{Cl}\right]$ and complex $\mathbf{I}$ in dichloromethane $\left(\sim 10^{-6}\right.$ $\left.\mathrm{M}, \lambda_{\mathrm{ex}}=450 \mathrm{~nm}\right)$.

\subsection{X-ray Structure of complex I}

Single crystals of complex I were obtained at $25{ }^{\circ} \mathrm{C}$ upon slow diffusion of hexane into the reaction mixture. The crystal data and structure refinement parameters of $[\mathrm{K}$ (crypt222) $]\left[\mathrm{Cr}^{\mathrm{III}}(\mathrm{TTP})(\mathrm{NCO})_{2}\right] \cdot 2 \mathrm{H}_{2} \mathrm{O}$ (complex I) are given in Table 1. The structure of negatively charged complex $\left[\mathrm{Cr}^{\mathrm{III}}(\mathrm{TTP})(\mathrm{NCO})_{2}\right]^{-}$together with the atom numbering scheme are shown in Figure 6, and some selected bond distances and angles of complex I as well as those of several related $\mathrm{Cr}(\mathrm{III})$ mesotetraarylporphyrins are listed in Table 5. The crystal system is orthorhombic with the noncentrosymmetric space group $C 222_{1}$. The chromium and the potassium atoms are located at special positions in a two-fold axis. The asymmetric unit of complex $\mathbf{I}$ contains one half of $\left[\mathrm{Cr}^{\mathrm{III}}(\mathrm{TTP})(\mathrm{NCO})_{2}\right]^{-}$ complex, one half of $\left[\mathrm{K}(\text { crypt-222) }]^{+}\right.$counterion and one water molecule. 
The chromium atom is located in the center of the tetrapyrrolic macrocycle and defines an axially distorted octahedral environment of four nitrogen atoms of porphyrin macrocycle and two axial nitrogen atoms of cyanate ligands (Figures 6 and 7). The metal atom is located within the porphyrin plane (the deviation of the chromium atom from the N4 plane is $0 \AA$ ) and N3-Cr-N3' angle forming by this center and the cyanate nitrogen atoms is equal to $175.90^{\circ}$. The average equatorial distance between the chromium(III) center and the nitrogen atoms of the porphyrin ring $(\mathrm{Cr}-\mathrm{Np})$ is $2.042(4) \AA$. It should be noted that this value is close to those of reported chromium(III) porphyrins (2.019-2.043 $\AA$ ) as well to $\mathrm{Cr}-\mathrm{Np}$ values of all other chromium porphyrins in which the oxidation degrees of the central metal are II, III, IV and V. At first glance this seems odd, because normally the value of this distance should decrease as the oxidation degree of the central ion increases. A possible explanation is the fact that the electronic configurations of the ground state of the cations $\mathrm{Cr}^{2+}, \mathrm{Cr}^{3+}, \mathrm{Cr}^{4+}$ and $\mathrm{Cr}^{5+}$ are respectively $3 \mathrm{~d}^{4}$, $3 \mathrm{~d}^{3}, 3 \mathrm{~d}^{2}$ and $3 \mathrm{~d}^{1}$. For all these complexes with octahedral $O_{h}$ or tetragonal $D_{4 h}$ symmetry, only the $\mathrm{d}_{\mathrm{xy}}$, $d_{y z}$ and $d_{x z}$ metal orbitals are occupied (assuming that the $\operatorname{Cr}(\mathrm{II})$ porphyrins are low-spin $(S=1)$ ) and consequently the $\mathrm{Cr}-\mathrm{Np}$ distances of these species are close.

The porphyrin macrocycle is almost planar in the crystals and the maximum displacement of the nitrogen atoms from the N4 plane being $\pm 0.009 \AA$. The displacement of the $\beta$-pyrrolic and the mesocarbon atoms from this plane do not exceed $\pm 0.063 \AA$ and $\pm 0.041 \AA$, respectively. The twist angles of the aryl rings lie in the range of $69.45-72.10^{\circ}$ that is typical for meso-tetraarylporphyrins.

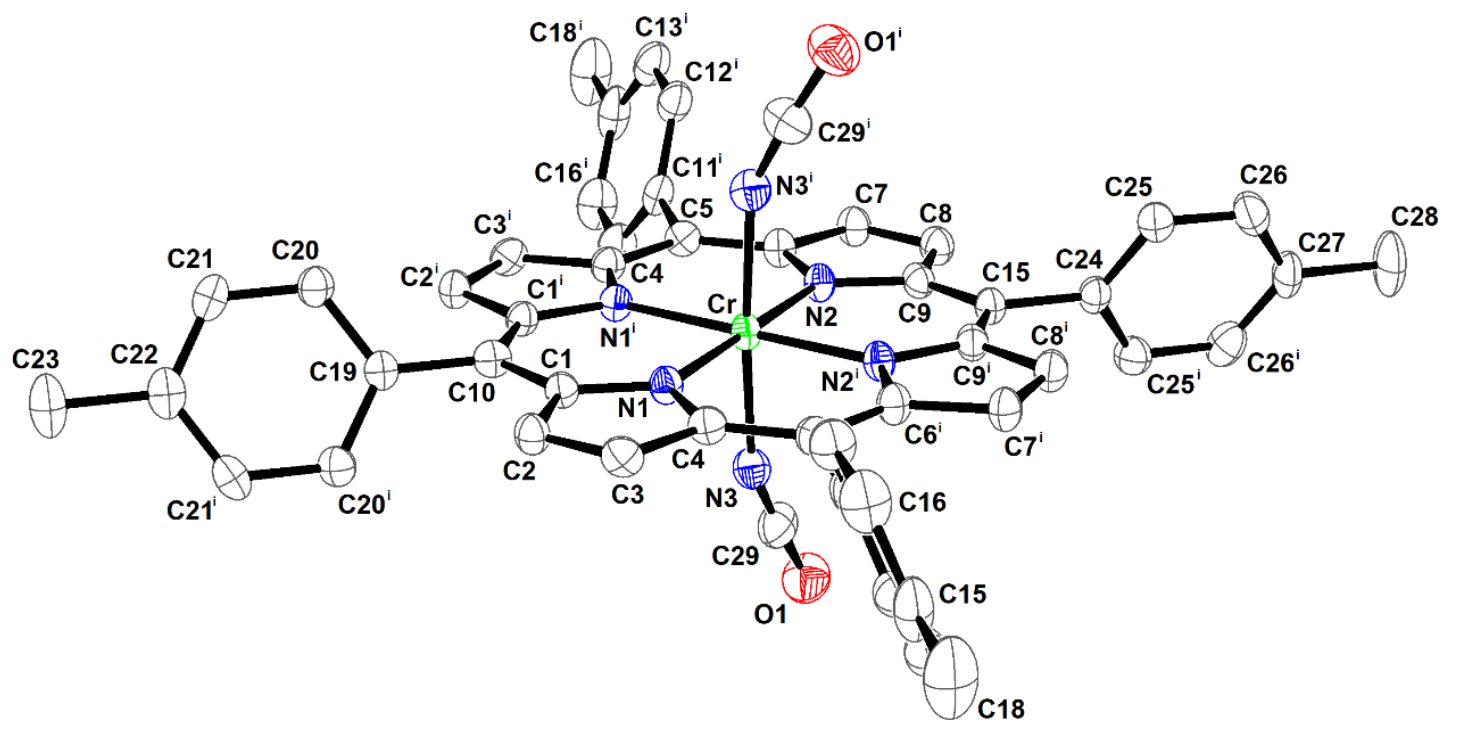


Figure 6. Ortep drawing of the $\left[\mathrm{Cr}^{\mathrm{III}}(\mathrm{TTP})(\mathrm{NCO})_{2}\right]^{-}$complex ion with thermal ellipsoids drawn at $30 \%$ probability. The hydrogen atoms are omitted for clarity and only the major position of the disordered cyanate axial ligand is shown.

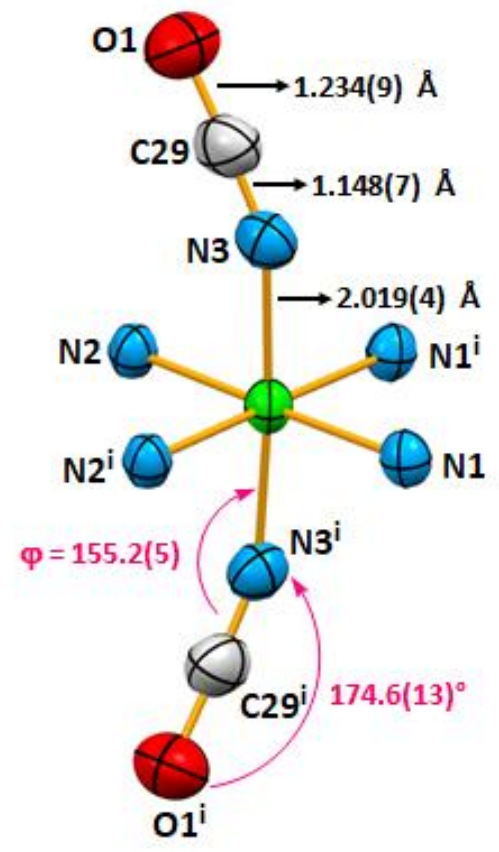

Figure 7. Coordination polyhedra of $\mathrm{Cr}^{3+}$ in $\left[\mathrm{Cr}^{\mathrm{III}}(\mathrm{TTP})(\mathrm{NCO})_{2}\right]^{-}$ion complex. Only the major position of the disordered axial ligand is shown.

The $\mathrm{Cr}(\mathrm{III})-\mathrm{N}(\mathrm{NCO})$ bond length equals to $2.019(4) \AA$ which is between those of the two (cyanato$\kappa N)$ chromium(III) non-porpohyrinic complexes reported in the literature: $\left[\mathrm{Cr}{ }^{\mathrm{III}}(\mathrm{NCO})_{2}\left(\mathrm{~L}_{1}\right)_{2}\right]^{-}\left(\mathrm{L}_{1}=\right.$ $N, N^{\prime}$-bis(3,5-di-tert-butylsalicylidene)-1,2-ethylenediamino) [54] and $\left[\mathrm{Cr}^{\mathrm{III}}(\mathrm{NCO})(\mathrm{NO})_{2}(\mathrm{Cp})\right](\mathrm{Cp}=$ cyclopentadienyl) [55] with values $2.025 \AA$ and $1.980 \AA$, respectively. The N3-C29 and C29--O1 distances in the $\mathrm{NCO}^{-}$axial ligands are 1.148(7) and 1.234(9) $\AA$, respectively that is very close to those of the (cyanato-kN)-porphyrinic and non-porphyrinic complexes (Table 6). These bond lengths are also similar to those of $\mathrm{KOCN}$ salt $(\mathrm{N}-\mathrm{C}=1.16 \AA$ and $\mathrm{C}-\mathrm{O}=1.27 \AA)$ that likely indicates a highly ionic character of the $\mathrm{Cr}-\mathrm{N}(\mathrm{NCO})$ bonds. The $\mathrm{NCO}^{-}$axial ligand of complex $\mathbf{I}$ is practically linear with a N3C29-O1 angle of $174.6(13)^{\circ}$ (only the major position is considered) as was observed for all known complexes bearing cyanate- $\kappa N$ ligand (Table 6). The $\mathrm{Cr}-\mathrm{N} 3-\mathrm{C} 29(\varphi)$ angle value of $155.2(5)^{\circ}$ lies within the typical range $\left(137-180^{\circ}\right)$ for various complexes with cyanate ligands (Table 6).

The charge of the $\left[\mathrm{Cr}^{\mathrm{III}}(\mathrm{TTP})(\mathrm{NCO})_{2}\right]^{-}$anionic complex is balanced by a $[\mathrm{K}(\mathrm{crypt}-222)]^{+}$ counterion. The average $\mathrm{K}-\mathrm{O}$ distance is equal to $2.858(4) \AA$, and the average $\mathrm{K}-\mathrm{N}$ bond length is $2.935(4) \AA$. 
Table 5. Selected bond lengths $[\AA]$ and angles $\left[{ }^{\circ}\right]$ for $\left[\mathrm{K}(\right.$ crypt-222) $]\left[\mathrm{Cr}^{\mathrm{III}}(\mathrm{TTP})(\mathrm{NCO})_{2}\right] \cdot 2 \mathrm{H}_{2} \mathrm{O}($ complex I) and related porphyrinic complexes.

Complex $\quad \mathrm{M}^{-} \mathrm{N}_{\mathrm{p}}{ }^{\mathrm{a}} \quad \mathrm{M}-\mathrm{X}_{\mathrm{L}}{ }^{\mathrm{b}}$ Ref.

Chromium(II) meso-arylporphyrins

$\begin{array}{llll}\left.\mathrm{Cr}^{\mathrm{II}}(\mathrm{TPP})\right]^{\mathrm{c}} & 2.033 & - & {[56]} \\ \left.\mathrm{Cr}^{\mathrm{II}}(\mathrm{TPP})(\mathrm{py})_{2}\right] & 2.019 / 2.034^{*} & 2.141 / 2.122^{\mathrm{c}} & {[57]}\end{array}$

Chromium(III) meso-arylporphyrins

$\begin{array}{llll}{\left[\mathrm{Cr}^{\text {III }}(\mathrm{TPP}) \mathrm{Cl}(1-\mathrm{MeIm})\right]^{\mathrm{d}, \mathrm{e}}} & 2.031 & 2.102(1-\mathrm{MeIm}) / 2.317(\mathrm{Cl}) & {[\mathbf{5 8}]} \\ {\left[\mathrm{Cr}{ }^{\text {III }}(\mathrm{TPP})\left(\mathrm{N}_{3}\right)(\mathrm{py})\right]^{\mathrm{d}}} & 2.031(5) & 2.004(5)(\text { azido }) / 2.135(5)(\mathrm{py}) & {[\mathbf{5 9}]} \\ {\left[\mathrm{Cr}{ }^{\text {III }}(\mathrm{TPP}) \mathrm{Cl}(\mathrm{py})\right]^{\mathrm{d}}} & 2.038(8) & 2.294(4)(\mathrm{Cl}) / 2.12(1)(\mathrm{py}) & {[\mathbf{6 1}]} \\ {[\mathrm{Cr}(\mathrm{TPP})(\mathrm{OPh})(\mathrm{THF})]^{\mathrm{d}}} & 2.037 & 2.069(\mathrm{THF}) / 1.943(\mathrm{OPh}) & {[61]} \\ {\left[\mathrm{Cr}{ }^{\text {III }}(\mathrm{TPP}) \mathrm{Cl}\left(\mathrm{H}_{2} \mathrm{O}\right)\right]^{\mathrm{d}}} & 2.043(2) & 2.3114(\mathrm{Cl}) / 2.057(2)\left(\mathrm{H}_{2} \mathrm{O}\right) & {[62]} \\ {\left[\mathrm{Cr}{ }^{\text {III }}(\mathrm{TTP})(\mathrm{NCO})_{2}\right]^{-}(\mathrm{I})} & 2.042(4) & 2.019(4) & \text { this work }\end{array}$

Chromium(IV) meso-arylporphyrins

$\begin{array}{lll}{\left[\mathrm{Cr}^{\mathrm{IV}}(\mathrm{TTP}) \mathrm{O}\right]} & 2.0320 & 1.5714\end{array}$

Chromium(V) meso-arylporphyrin

$\begin{array}{lll}{\left[\mathrm{Cr}^{\mathrm{V}}(\mathrm{TTP}) \mathrm{N}\right]} & 2.040 & 1.5624\end{array}$

[64]

${ }^{\mathrm{a}}: \mathrm{M}-\mathrm{Np}=$ average distance between equatorial pyrrole nitrogen and cobalt atoms, ${ }^{\mathrm{b}}: \mathrm{M}-\mathrm{X}_{\mathrm{L}}=$ metal - axial ligand distance, ${ }^{c}$ : the asymmetric unit contains two molecules, ${ }^{\mathrm{d}}:$ TPP $=$ meso-tetraphenylporphyrinate, ${ }^{\mathrm{e}}: 1-\mathrm{MeIm}=1$ methylimidazole. 
Table 6. Selected bond lengths $[\AA]$ and angles $\left[{ }^{\circ}\right]$ for metal complexes with cyanate- $\kappa N$ ligand.

\begin{tabular}{|c|c|c|c|c|c|c|}
\hline Complex & \begin{tabular}{l}
$\mathrm{M}-\mathrm{N}(\mathrm{NCO})$ \\
\hdashline$[\AA]$
\end{tabular} & $\begin{array}{l}\mathrm{N}-\mathrm{C} \\
{[\AA]}\end{array}$ & $\begin{array}{l}\mathrm{C}-\mathrm{O} \\
{[\AA]}\end{array}$ & $\begin{array}{l}\text { N-C-O } \\
-[\text { deg.] }\end{array}$ & $\begin{array}{l}\text { M-N-C }(\varphi) \\
--{ }^{d e g .]}\end{array}$ & Ref. \\
\hline \multicolumn{7}{|c|}{ Cyanato- $\kappa N$ metalloporphyrins } \\
\hline$\left[\mathrm{Cr}^{\mathrm{III}}(\mathrm{TTP})(\mathrm{NCO})_{2}\right]^{-}$ & $2.019(4)$ & $1.148(7)$ & $1.234(9)$ & $174.6(13)$ & $155.2(5)$ & t.w. \\
\hline$[\mathrm{Mg}(\mathrm{TPP})(\mathrm{NCO})]^{-\mathrm{a}}$ & $2.0471(17)$ & $1.165(2)$ & $1.210(2)$ & $178.34(2)$ & $157.34(15)$ & {$[65]$} \\
\hline$[\mathrm{Zn}(\mathrm{TTP})(\mathrm{NCO})]^{-\mathrm{a}}$ & $2.0293(3)$ & $1.200(5)$ & $1.163(4)$ & 179.66 & $137.00(3)$ & {$[66]$} \\
\hline$\left[\mathrm{Co}^{\mathrm{III}}(\mathrm{TPP})(\mathrm{NCO})_{2}\right]^{-\mathrm{a}}$ & $1.905 / 1.919$ & $1.151 / 1.155$ & $1.202 / 1.193$ & $178.6 / 176.9$ & $159.8 / 144.6$ & 67] \\
\hline$\left[\mathrm{Mn}^{\mathrm{III}}(\mathrm{TPP})(\mathrm{NCO})\right]^{\mathrm{a}}$ & $2.029(5)$ & $1.124(9)$ & $1.200(9)$ & 179.25 & $150.0(5)$ & {$[68]$} \\
\hline \multirow[t]{2}{*}[\mathrm{Mn}^{\mathrm{IV}}(\mathrm{TPP})(\mathrm{NCO})]{$^{\mathrm{a}}$} & $1.934(3)$ & $1.171(5)$ & $1.193(5)$ & $176.5(4)$ & $150.0(5)$ & {$[68]$} \\
\hline & $1.918(3)$ & $1.164(5)$ & $1.223(5)$ & $176.3(5)$ & $136.5(3)$ & \\
\hline \multirow[t]{2}{*}[\mathrm{Fe}^{\mathrm{II}}(\mathrm{TpivPP})(\mathrm{NCO})]{$^{-\mathrm{b}}$} & $2.005(3)$ & $1.150(5)$ & $1.200(5)$ & $179.9(5)$ & 133.1(3) & [69] \\
\hline & \multicolumn{6}{|c|}{ Non-porphyrinic cyanato- $\kappa N$ chromium(III) complexes } \\
\hline$\left[\mathrm{Cr}^{\mathrm{III}}(\mathrm{NCO})_{2}\left(\mathrm{~L}_{1}\right)_{2}\right]^{-\mathrm{c}}$ & 2.025 & 1.173 & 1.209 & 177.01 & 162.08 & {$[54]$} \\
\hline \multicolumn{2}{|c|}{$\left[\mathrm{Cr}^{\mathrm{III}}(\mathrm{NCO})(\mathrm{NO})_{2}(\mathrm{Cp})\right]^{\mathrm{d}} 1.980$} & 1.126 & 1.180 & 178.59 & 180 & {$[65]$} \\
\hline
\end{tabular}

${ }^{\mathrm{a}}: \mathrm{TPP}=$ meso-tetraphenylporphyrinate, ${ }^{\mathrm{b}}:$ TpivPP $=\alpha, \alpha, \alpha, \alpha$-tetrakis $\left(o\right.$-pivalamidophenyl)porphyrinate, ${ }^{\mathrm{c}}: \mathrm{L}_{1}=N, N-$ bis(3,5-di-tert-butylsalicylidene)-1,2-ethylenediamine, ${ }^{\mathrm{d}}: \mathrm{Cp}=$ cyclopentadienyl.

As show in Figure 8, in the crystal, $\left[\mathrm{Cr}^{\mathrm{III}}(\mathrm{TTP})(\mathrm{NCO})_{2}\right]^{-}$species and $[\mathrm{K}(\mathrm{crypt}-222)]^{+}$counterions are arranged into columns along the [100] direction. The crystal lattice of complex $\mathbf{I}$ is stabilized by numerous intermolecular contacts : (i) the oxygen $\mathrm{O} 1$ of the major position of the disordered cyanate- $\kappa N$ axial ligand forms a hydrogen bond with the oxygen $\mathrm{O} 5$ of water molecule with a $\mathrm{O} 5{ }^{-} \mathrm{H} 1 \mathrm{O} 5{ }^{\cdots} \mathrm{O} 1$ and O5 $-\mathrm{H}_{2} \mathrm{O}_{5} \cdots \mathrm{O} 1$ distances of 2.920 (18) and 2.920 (18) $\AA$, respectively, (ii) weak intermolecular contacts are observed between the same $\mathrm{O} 1$ atom and $\mathrm{C} 23$ atom of the para-methyl substituent of phenyl group of a porphyrin macrocycle and the $\mathrm{C} 37$ atom of the closest cryptand-222 molecule with $\mathrm{C} 23{ }^{-} \mathrm{H} 23 \mathrm{C}^{\cdots} \mathrm{O} 5$

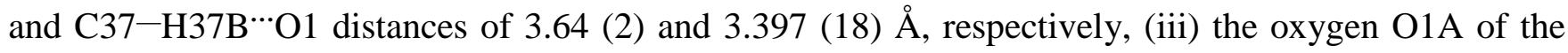
minor position of the disordered cyanate- $\kappa N$ axial ligand is also weakly $\mathrm{H}$-bonded to $\mathrm{C} 30$ and $\mathrm{C} 36$ atoms of the neighboring cryptand-222 molecule with distances of 3.332 (18) and 3.594 (18) $\AA$, respectively, (iv) the $\mathrm{N} 3$ nitrogen atom of the $\mathrm{OCN}^{-}$axial ligand is weakly bonded to the $\mathrm{C} 36$ carbon 
atom of a nearby cryptand-222 molecule with a $\mathrm{C} 36-\mathrm{H} 36 \mathrm{~A}^{\cdots} \mathrm{N} 3$ distance of 3.606 (18) $\AA$, (v) the oxygen $\mathrm{O} 4$ of a cryptand-222 molecule is weakly bonded to the carbon $\mathrm{C} 17$ of phenyl ring belonging to neighboring porphyrin molecule with a $\mathrm{C} 17-\mathrm{H} 17^{\cdots} \mathrm{O} 4$ distance of 3.876 (18) $\AA$ and (vi) the $\mathrm{C} 36$ atom of a cryptand-222 and the centroid $\mathrm{Cg} 2$ of the pyrrole ring $\mathrm{N} 1 / \mathrm{C} 1-\mathrm{C} 4$ are involved in a $\mathrm{C}-\mathrm{H} \cdots \mathrm{Cg}(\pi-$ ring) intermolecular interaction with a $\mathrm{C} 36^{-}-\mathrm{H} 36^{\cdots \cdots} \mathrm{Cg} 2$ distance value of 3.497 (6) $\AA$ (Table S1).

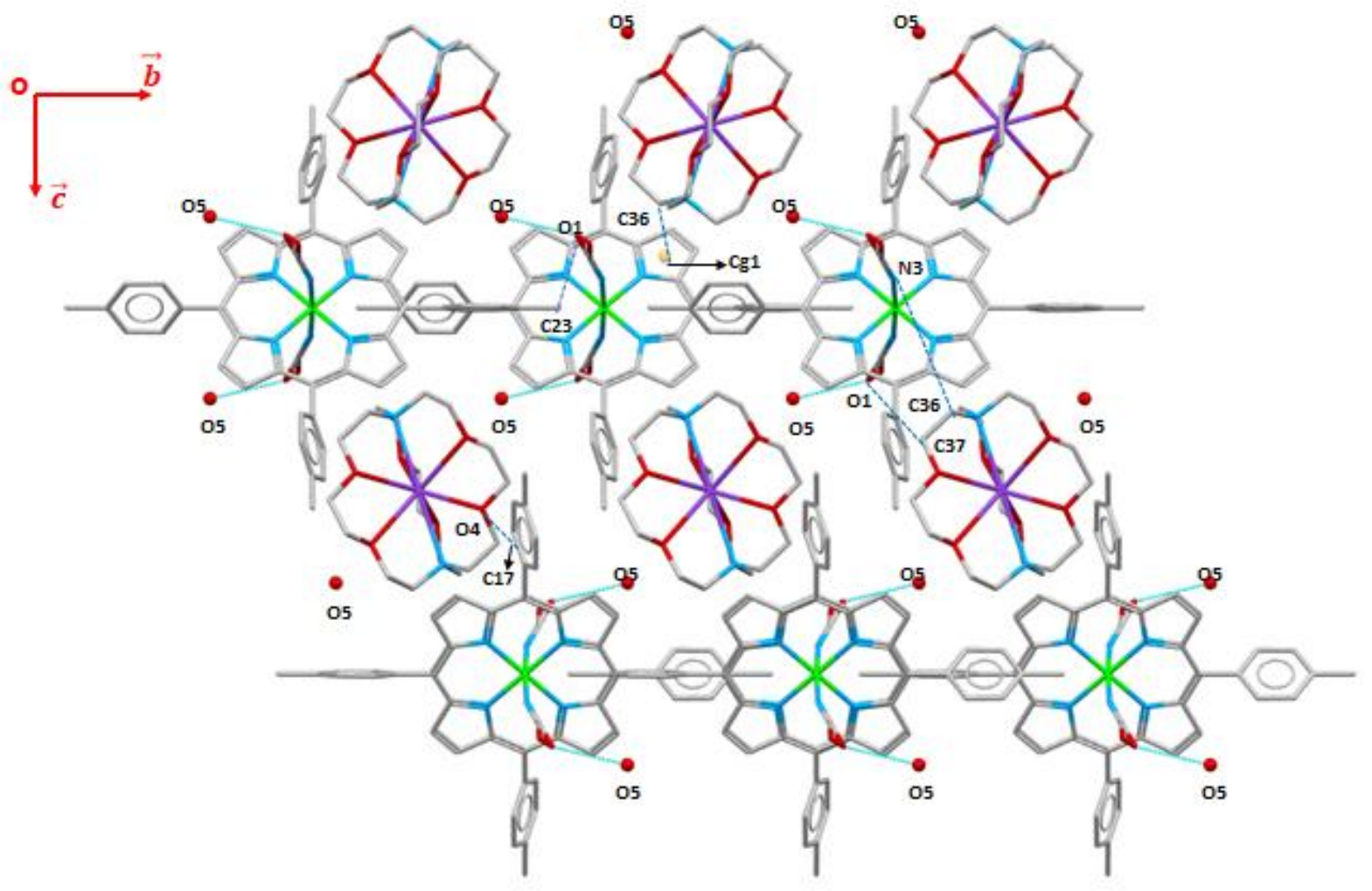

Figure 8. Molecular packing in crystals of complex I view along the [100] direction.

It is noteworthy that regular voids which are parallel to the [100] direction are observed in the studied crystals (Figure 9). However, these voids present only approximately $1.8 \%$ of cell volume that is equal to a total volume of $120 \AA^{3}$ per cell. 


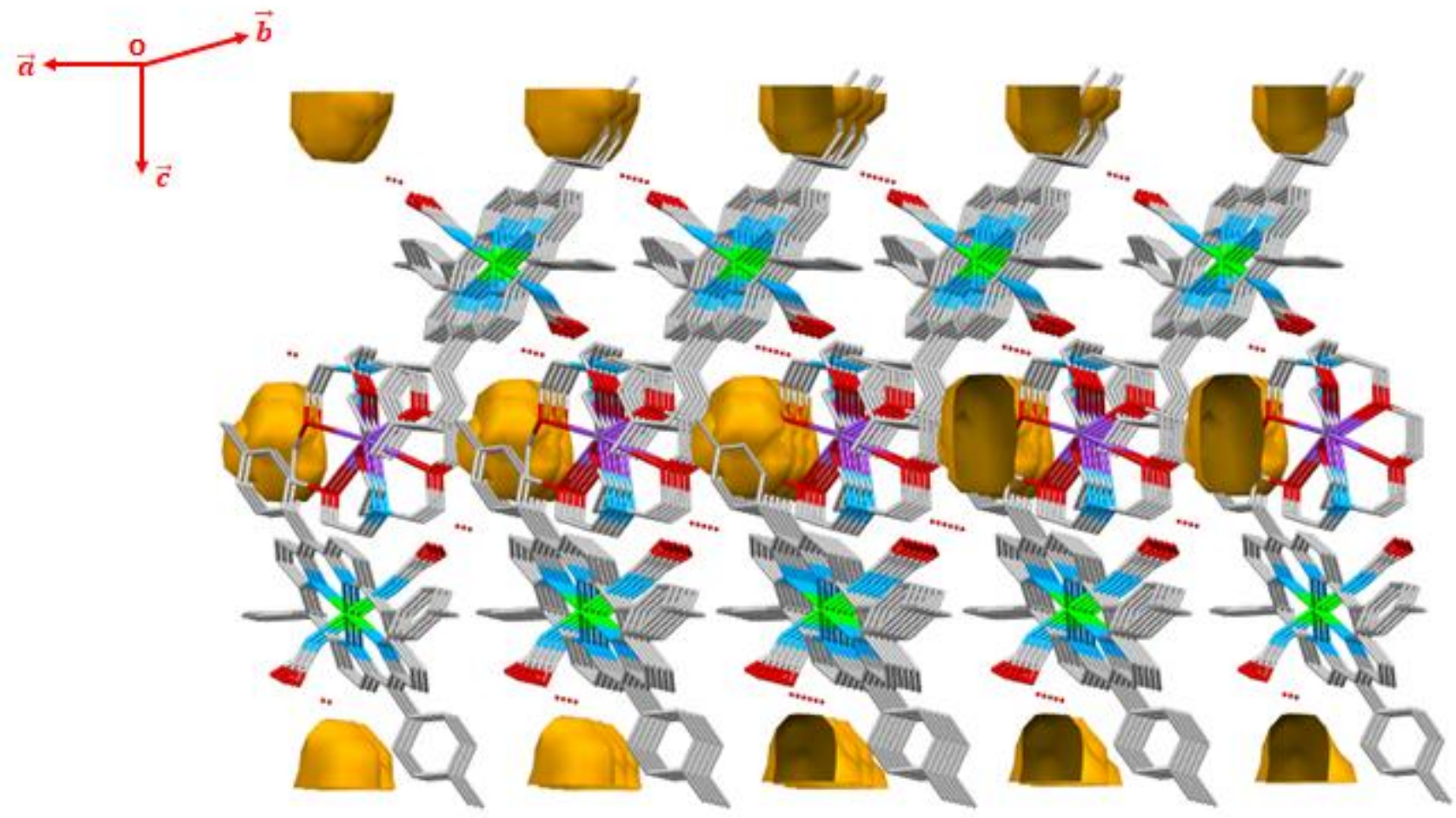

Figure 9. Packing diagram of complex I showing the voids in the structure represented in orange. Voids were calculated for a ball radius of $1.2 \AA$ and a grid of $0.7 \AA$.

\subsection{Hirshfeld Surface Analysis}

Hirshfeld surface (HS) analysis and 2D fingerprint plots are considered as important computational data derived from single crystal X-ray analysis which provide a visualization of the intermolecular interactions within the crystal lattice [70,71]. These calculations are useful to understand profoundly the role of hydrogen bonding as well as other intermolecular short contacts in the stability of the crystal lattice. The Hirshfeld surface of complex I mapped over the $d_{\text {norm }}$ range from -0.2858 to $1.6287 \AA$ is represented in Figure 10. The circular depression (in red) shown in the HS are indicative of O-H...O, $\mathrm{C}-\mathrm{H} \ldots \mathrm{H}$ and $\mathrm{C}-\mathrm{H} \ldots \mathrm{N}$ hydrogen bonding while the regions in light color on the $\mathrm{HS}$ indicate weaker interactions than hydrogen bonds (Figure 10).

The Shape-index plots cover the range of $[-1.0 ; 1.0] \AA$ and the curvedness plots concern the domain between -4.0 and $0.4 \AA$. The red and blue triangle pairs represented in Figure 11a illustrates the Sharpindex surfaces which are indicative for $\pi$-stacking interactions. The curvedness map shown in Figure 
$11 \mathrm{~b}$ presents no flat surface patches that indicates the absence of stacking interaction between the aromatic fragments. According to 2D fingerprint plots of complex I shown in Figure S5, most important intermolecular interactions are $\mathrm{H}^{\cdots} \mathrm{H}$ contacts $(61.4 \%)$. The $\mathrm{C} \ldots \mathrm{H} / \mathrm{H} \ldots \mathrm{C}, \mathrm{O} \ldots \mathrm{H} / \mathrm{H} \ldots \mathrm{O}$ and $\mathrm{N} \ldots \mathrm{H} / \mathrm{H} \ldots \mathrm{N}$ interactions comprised $21.3 \%, 13.3 \%$ and $3.6 \%$ of the HS, respectively.

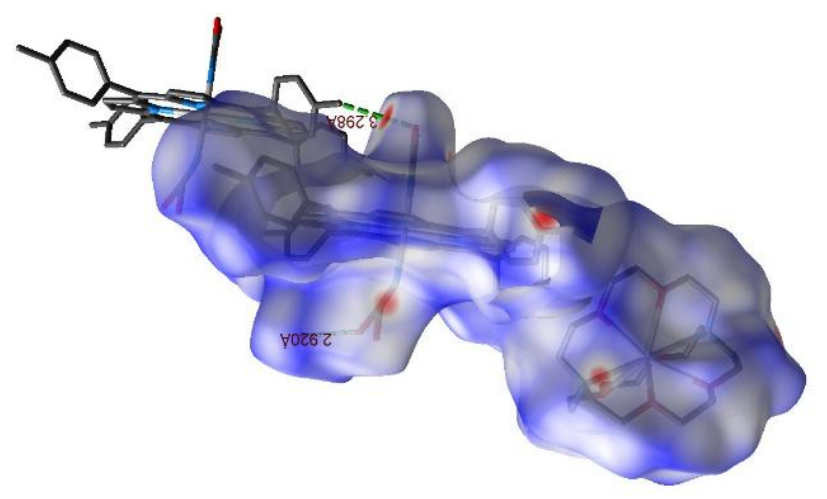

Figure 10. Hirshfeld surfaces of complex I mapped over $\mathrm{d}_{\text {norm }}$.

(a)

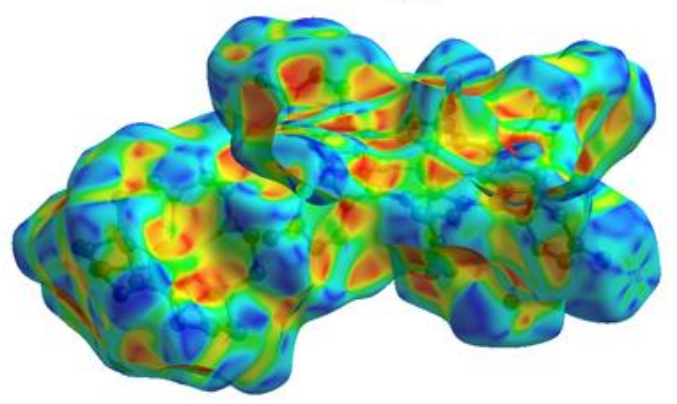

(b)

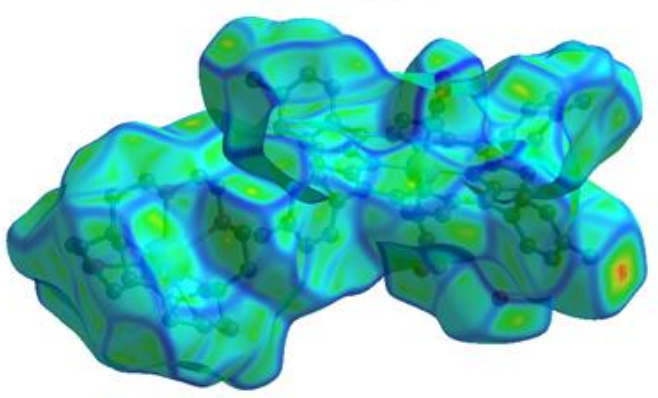

Figure 11. Hirshfeld surfaces of complex I mapped over (a): Sharp index and (b): Curvedness.

\subsection{Cyclic voltammetry}

Back in the early seventies, K. M. Kadish [72], C. A. Reed [73], A. Summerville [74] and other researchers reported several cyclic voltammetry investigations on chromium(III) metalloporphyrins such as $\left[\mathrm{Cr}^{\mathrm{III}}(\mathrm{Porph}) \mathrm{Cl}\right][75],\left[\mathrm{Cr}^{\mathrm{III}}(\mathrm{Porph})(\mathrm{OH})\right][72]$ and $\left[\mathrm{Cr}^{\mathrm{III}}(\mathrm{Porph})\left(\mathrm{ClO}_{4}\right)\right]$ [76]. Kadish et al. [75] have demonstrated that $\left[\mathrm{Cr}^{\mathrm{III}}(\mathrm{TPP}) \mathrm{Cl}\right]$ exhibits three one-electron reduction waves in non-coordinating 
dichloromethane solvent (Table 6). The first one corresponds to the $\mathrm{Cr}(\mathrm{III}) / \mathrm{Cr}$ (II) reduction accompanied by a chloride ion dissociation (Eq. 1, (R4)) (Scheme 1). Then two porphyrin macrocycle reductions are observed ( Eq. 2 (R5,05) and Eq. 3 (R6,06)). In the cathodic region of the voltammogram of $\left[\mathrm{Cr}^{\mathrm{III}}(\mathrm{TPP}) \mathrm{Cl}\right]$, the first quasi-reversible one-electron oxidation wave was attributed to the $\mathrm{Cr}(\mathrm{III}) / \mathrm{Cr}(\mathrm{IV})$ oxidation $(\mathbf{O}, \mathbf{R 1})$ and two successive quasi-reversible one-electron oxidation waves $(\mathbf{O 2}, \mathbf{R 2})$ and $(\mathbf{O 3}, \mathbf{R 3})$ were assigned to the porphyrin ring oxidation (Table 6).

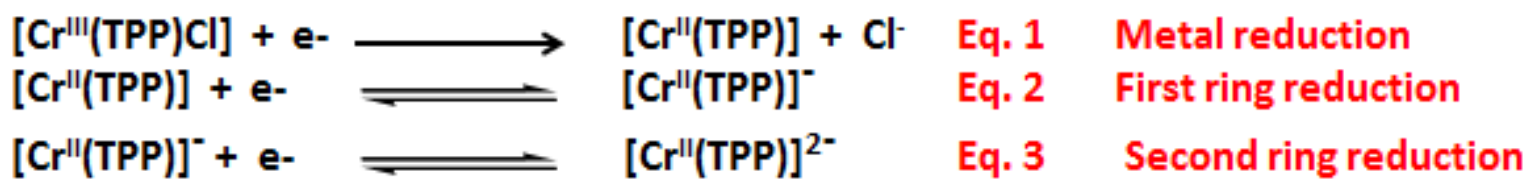

Scheme 1. Electrochemical reduction of $\left[\mathrm{Cr}^{\mathrm{III}}(\mathrm{TPP}) \mathrm{Cl}\right]$ in dichloromethane [75]. 
Table 6. Potentials (in V vs SCE) of investigated complex I and a selection of related chromium(III) metalloporphyrins.

\begin{tabular}{|c|c|c|c|c|c|c|c|}
\hline \multirow{3}{*}{$\begin{array}{l}\text { Compound } \\
\text { (Solvent) }\end{array}$} & \multirow{2}{*}{$\begin{array}{l}\text { Oxidation } \\
\text { Metal Oxid. } \\
(\mathrm{O} 1, \mathrm{R} 1)\end{array}$} & \multirow[b]{2}{*}{$\begin{array}{l}1^{\text {st }} \text { Porph. Oxid. } \\
(\mathrm{O} 2, \mathrm{R} 2)\end{array}$} & \multirow[b]{2}{*}{$\begin{array}{l}2^{\text {nd }} \text { Porph. Oxid. } \\
(\mathrm{O} 3, \mathrm{R} 3)\end{array}$} & \multicolumn{2}{|l|}{ Reduction } & & \multirow[t]{2}{*}{ Ref. } \\
\hline & & & & $\begin{array}{l}\text { Metal Red. } \\
(\mathrm{R} 4, \mathrm{O} 4)\end{array}$ & $\begin{array}{l}1^{\text {st }} \text { Porph. Red. } \\
\text { (R5,O5) }\end{array}$ & $\begin{array}{l}2^{\text {nd }} \text { Porph. Red. } \\
(\text { R6,O6) }\end{array}$ & \\
\hline & $\mathrm{E}_{1 / 2}^{\mathrm{a}}$ & $\mathrm{E}_{1 / 2}{ }^{\mathrm{a}}$ & $\mathrm{E}_{1 / 2}{ }^{\mathrm{a}}$ & $\mathrm{E}_{\mathrm{cp}}^{\mathrm{b}}$ & $\mathrm{E}_{1 / 2}{ }^{\mathrm{a}}$ & $\mathrm{E}_{1 / 2}{ }^{\mathrm{a}}$ & \\
\hline \multicolumn{8}{|l|}{$\left[\mathrm{Cr}^{\mathrm{III}}(\mathrm{OEP})(\mathrm{OH})\right]^{\mathrm{c}}$} \\
\hline $\begin{array}{l}(\mathrm{PrCN})) \\
{\left[\mathrm{Cr}^{\mathrm{III}}(\mathrm{TPP}) \mathrm{Cl}\right]^{\mathrm{d}}}\end{array}$ & 0.79 & 0.99 & 1.22 & -1.35 & -1.40 & - & [74] \\
\hline$\left(\mathrm{Me}_{2} \mathrm{SO}\right)$ & - & - & - & -0.86 & -1.23 & -1.70 & [75] \\
\hline (DMF) & - & - & - & -0.82 & -1.09 & -1.72 & [77] \\
\hline$\left(\mathrm{CH}_{2} \mathrm{Cl}_{2}\right)$ & - & - & - & $-1.01^{\mathrm{b}}$ & -1.20 & -1.86 & [75] \\
\hline \multicolumn{8}{|l|}{$\left[\mathrm{Cr}^{\mathrm{III}}(\mathrm{TPP})(\mathrm{OMe})\right]^{\mathrm{d}}$} \\
\hline (DMSO) & - & - & - & -0.86 & -1.23 & -1.70 & [77] \\
\hline$\left[\mathrm{Cr}^{\mathrm{III}}(\mathrm{TPP})\left(\mathrm{ClO}_{4}\right)\right]^{\mathrm{d}}$ & & & & & & & \\
\hline$(\mathrm{MeCN})$ & 1.08 & 1.42 & - & -0.73 & -1.14 & -1.78 & [76] \\
\hline (DMF) & 1.14 & - & - & -0.84 & -1.10 & -1.75 & [76] \\
\hline $\begin{array}{l}{\left[\mathrm{Cr}^{\mathrm{III}}(\mathrm{TTP})(\mathrm{NCO})_{2}\right]^{-}(\mathbf{I})} \\
\left(\mathrm{CH}_{2} \mathrm{Cl}_{2}\right)\end{array}$ & 0.92 & 1.11 & 1.38 & -1.05 & -1.14 & -1.78 & this work \\
\hline
\end{tabular}

${ }^{a}: \mathrm{E}_{1 / 2}=$ half-wave potential, ${ }^{\mathrm{b}}: \mathrm{E}_{\mathrm{cp}}=$ cathodic potential, ${ }^{\mathrm{c}}: \mathrm{OEP}=$ octaethylporphyrinate. $^{\mathrm{d}}: \mathrm{TPP}=$ meso-tetraphenylporphyrinate. 
The cyclic voltammogram of the bis $($ cyanato- $\kappa N)$ chromium(III) porphyrin prepared by us is similar to that of $\left[\mathrm{Cr}^{\mathrm{III}}(\mathrm{TPP}) \mathrm{Cl}\right]$ (Figure 12). In the negative potential region, three one-electron reduction waves are observed. The first irreversible wave at $-1.01 \mathrm{~V}$ corresponds to the $\mathrm{Cr}(\mathrm{III}) / \mathrm{Cr}$ (II) reduction (Eq 1 (R4), Scheme 1) and two quasi-reversible reductions waves $(\mathbf{R 5}, \mathbf{0 5})$ and $(\mathbf{R 6 , 0 6})$ with values of -1.20 and $-1.86 \mathrm{~V}$ are attributed to the porphyrin macrocycle reductions (Eq 2 and 3, Scheme 1). The first quasi-reversible one-electron oxidation wave at $0.92 \mathrm{~V}$ corresponds to the $\mathrm{Cr}(\mathrm{III}) / \mathrm{Cr}(\mathrm{IV})$ oxidation. The oxidation at $\mathrm{E}_{1 / 2}=1.11$ and $1.38 \mathrm{~V}$ are rather similar to those reported for pentacoordinated chrome(III) porphyrins (Table 6) and thus, can be attributed to the stepwise oxidation of the porphyrin macrocycle.-The data summarized in Table 6 allow for the conclusion that metal center is harder to reduce and easer to oxidize in complex $\mathbf{I}$ than in the $\left[\mathrm{Cr}{ }^{\mathrm{III}}(\mathrm{TPP})(\mathrm{X})\right]\left(\mathrm{X}=\mathrm{Cl}^{-}, \mathrm{OH}^{-}\right.$or $\left.\mathrm{ClO}_{4}{ }^{-}\right)$complexes that is expected for a negatively charged species (Table 6).

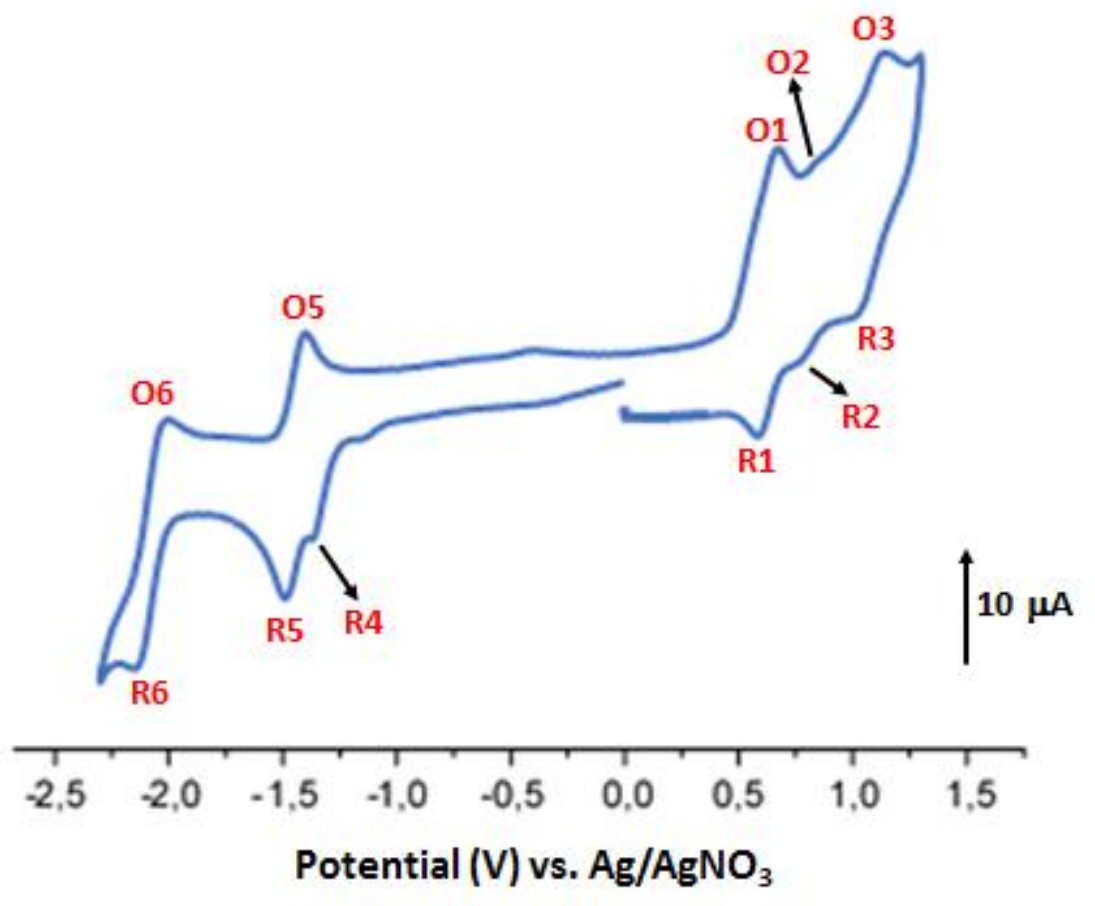

Figure 12. Cyclic voltammogram of complex $\mathbf{I}$ in a $\sim 10^{-3} \mathrm{M}$ dichloromethane solution containing 0.2 M TBAP. (100 mV.s ${ }^{-1}$, vitreous carbon working electrode $(\varnothing=2 \mathrm{~mm})$. 


\subsection{DFT calculations of complex I}

In order to get insight into the electronic structure and the reactivity of chromium(III) complex I, the FMOs and reactivity descriptors (such as electron affinity, chemical softness, ionization potential, chemical softness) are determined.

The HOMO orbital represents the highest occupied molecular orbital of the valence band (BV) while LUMO orbital is the lowest unoccupied molecular orbital of the conduction band (BC). These orbitals help to estimate the chemical stability and identify the reactivity sites of molecules. The energy separation value between these two orbitals is known as the Gap energy is also very important to get useful information about the electronic properties of studied compounds. The frontier orbitals HOMO and LUMO as well as the Gap energy calculated in the gas phase by using TD-DFT approach are shown in Figure 13 in which the green colour indicates the negative phase, while the positive phase is represented by the red colour.

A theoretical study on $\left[\mathrm{Cr}^{\mathrm{III}}(\mathrm{TTP}) \mathrm{Cl}\right]$ had to be also carried out to promote understanding of computational results. Unfortunately, crystallographic data of this complex are not available and we performed the calculations for its closest analogue $\left[\mathrm{Cr}(\mathrm{TPP}) \mathrm{Cl}\left(\mathrm{H}_{2} \mathrm{O}\right)\right]$ whose $\mathrm{X}$-ray molecular structure is available [78].

Table 7 summarizes the values of the reactivity descriptors (the energies of the frontier molecular orbitals $\left(\mathrm{E}_{\mathrm{HOMO}}, \mathrm{E}_{\mathrm{LUMO}}\right)$, the gap energies, the chemical potential $(\mu)$, the chemical hardness $(\eta)$, the electrophilicity $(\chi)$, the ionization potential $(I)$, the electron affinity $(A)$ and the global softness $(S)$ of complex I and $\left[\mathrm{Cr}^{\mathrm{III}}(\mathrm{TPP}) \mathrm{Cl}\left(\mathrm{H}_{2} \mathrm{O}\right)\right]$. All these parameters are linked to the energies of the FMOs by the electronic affinity $A E=E_{L U M O}$ and the ionization potential $P I=-E_{\text {Номо }}$. These parameters are defined as follows

$$
\begin{aligned}
& E-\operatorname{Gap}=E_{\text {HомO }}-E_{\text {LUMO }} \\
& \mu=-1 / 2(I+A)) \\
& \eta=1 / 2(I-A) \\
& \psi=\frac{\mu^{2}}{2 \eta} \\
& I=-E_{\text {HOMO }} \\
& A=-E_{\text {LUMO }} \\
& S=\frac{1}{2 \eta}
\end{aligned}
$$


The polarizability is directly related to its Gap energy; a lower polarizability is indicative of a higher stability of compounds and vis versa. The chemical softness and hardness can also be used for a preliminary estimation of the reactivity. The softer a molecule is, the more reactive it is. For a chemical species, a small Gap energy indicates that this species is soft while a large Gap energy is an indication that this compound is inert.

The calculated Gap energy values of complex I (Table 7, Figure 13) is equal to $2.124 \mathrm{eV}$, which is higher than the experimental optical Gap (Eg-opt) $(1.971 \mathrm{eV})$. This value is exceeded the theoretical Gap energy of $\left[\mathrm{Cr}^{\mathrm{III}}(\mathrm{TPP})\left(\mathrm{Cl}\left(\mathrm{H}_{2} \mathrm{O}\right)\right](\mathrm{E}-\mathrm{Gap}=1.819 \mathrm{eV})(\right.$ Table 7 , Figure S6). Therefore, complex $\mathbf{I}$ is likely less reactive than the complex bearing chloride as an axial ligand. This is also confirmed by a comparison of hardness and softness of these two chromium(III) porphyrins $\left[\mathrm{Cr}^{\mathrm{III}}(\mathrm{TPP}) \mathrm{Cl}\left(\mathrm{H}_{2} \mathrm{O}\right)\right]$ are $\sim 0.53$ and 0.55 , respectively for softness and $\sim 1.06 \mathrm{eV}$ and $0.91 \mathrm{eV}$, respectively for hardness).

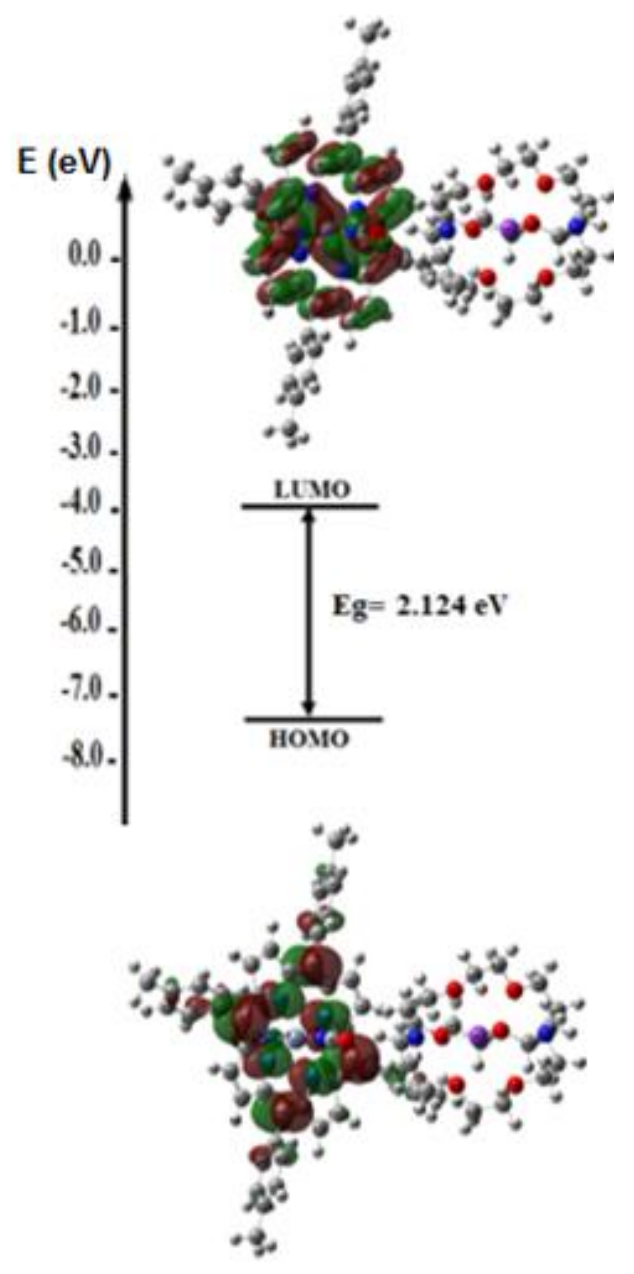


Figure 13. HOMO-LUMO molecular orbitals of complex I using TD-DFT calculations.

Table 7. Calculated HOMO, LUMO and Gap energy values and some global reactivity descriptors for complex $\mathbf{I}$.

\begin{tabular}{lll}
\hline Parameters & Complex I & {$\left[\mathrm{Cr}^{\mathrm{III}}(\mathrm{TPP}) \mathrm{Cl}\left(\mathrm{H}_{2} \mathrm{O}\right)\right]$} \\
\hline $\mathrm{E}_{\mathrm{HOMO}}(\mathrm{eV})$ & -1.867 & -5.235 \\
$\mathrm{E}_{\mathrm{LUMO}}(\mathrm{eV})$ & -3.991 & -3.416 \\
$\left.\Delta \mathrm{E}\left[\mathrm{E}_{\mathrm{HOMO}}-\mathrm{E}_{\mathrm{LUMO}}\right)\right]:$ E-Gap $(\mathrm{eV})$ & 2.124 & 1.819 \\
\hline & & \\
& Reactivity descriptors & \\
\hline & & -4.325 \\
& -2.929 & 0.909 \\
Chemical potential $\mu(\mathrm{eV})$ & 1.062 & 4.325 \\
Chemical hardness $\eta(\mathrm{eV})$ & 2.929 & 5.235 \\
electrophilicity $(\chi)$ & 3.991 & 3.416 \\
$I$ (ionization potential) $(\mathrm{eV})$ & 1.867 & 0.550 \\
$A$ (electron affinity $)(\mathrm{eV})$ & 0.531 & \\
Softness $S(\mathrm{eV})^{-1}$ & & \\
& &
\end{tabular}




\subsection{Molecular electronic potential analysis of (complex I)}

In Figure 14 are illustrated the Molecular Electronic Potential (MEP) maps for complex I and $\left[\mathrm{Cr}^{\mathrm{III}}(\mathrm{TPP}) \mathrm{Cl}\left(\mathrm{H}_{2} \mathrm{O}\right)\right]$ obtained by using DFT/B3LYP/LanL2DZ process. These maps also allow to get insight into the reactivity of molecular systems analyzing electrophilic (regions of positive electrostatic potential) and nucleophilic (regions of negative electrostatic potential) sites of the molecule as well as hydrogen bond interactions. In general, any intra- or intermolecular non-covalent interaction can be characterized as an interaction between an electrophilic site and a nucleophilic site. For a MEP map, the red color refers to the potential negative values while the blue color refers to the potential positive values while the orange and yellow colors are used for intermediate potentials. For the MEP map for complex I, the color code is between $-9.929 .10^{-2}$ u.a. (red color) and $9.929 .10^{-2}$ (blue color). Okulik et al.,[79] reported that the red color represents the strongest repulsion in the MEP map while the blue arias indicate an electrophilic reactivity. The green color corresponds to a zero potential. As can be clearly seen, the PEM study of the mentioned compound led to the identification of two zones enriched in electrons (red color). As shown by Figure 14, the red color regions are located around the cyanate$\kappa N$ and the chloride axial ligands for complex I and $\left[\mathrm{Cr}^{\mathrm{III}}(\mathrm{TTP}) \mathrm{Cl}\left(\mathrm{H}_{2} \mathrm{O}\right)\right]$, respectively indicating that these sites present rather high electrophilic reactivity.

(a)

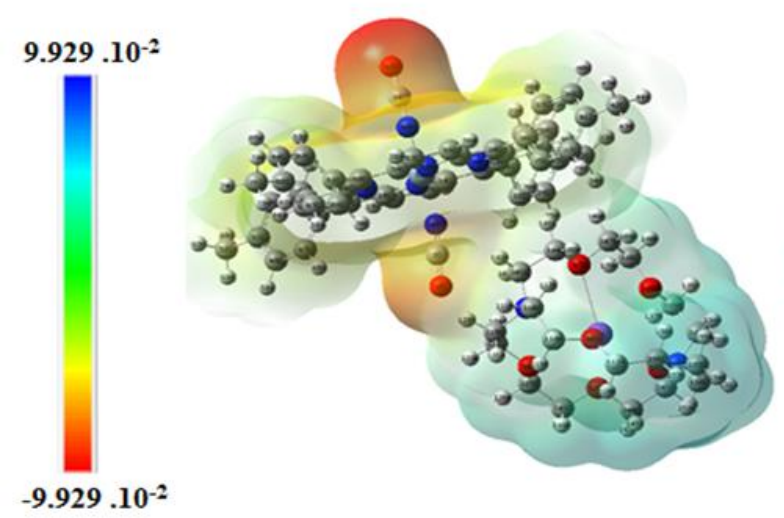

(b)

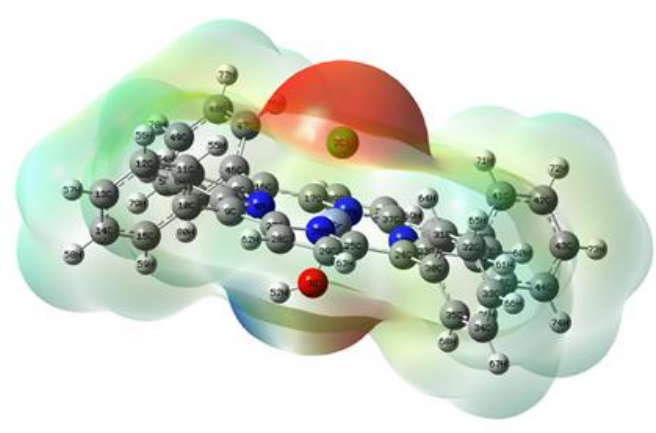

Figure 14. The mapped molecular electrostatic potential (MEP) of complex I : (a) and $\left[\mathrm{Cr}^{\mathrm{III}}(\mathrm{TPP}) \mathrm{Cl}\left(\mathrm{H}_{2} \mathrm{O}\right)\right]:(\mathbf{b})$.

\subsection{Degradation of Rhodamine B}


Free-base porphyrins and their metal complexes are known as efficient catalysts for oxidation reactions [80,81]. To get insight into catalytic properties of the newly synthesized complex $\mathbf{I}$ the oxidative degradation of $\mathrm{RhB}$ was investigated using hydrogen peroxide and molecular oxygen as oxidants. To our knowledge, catalytic activity of chromium(III) complexes in decomposition of organic dyes is scarcely studied and was reported only in our recent work where hydrogen peroxide was used as an oxidant [82]. In this work we compared the rate of RhB decolorization in the presence of complex I and [Cr(TTP)Cl] starting compound which differ one from another only in the axial ligands coordinated to the chromium center. We attempt to demonstrate that these complexes accelerate the RhB degradation and that their catalytic activity is influenced by axial ligands as it was already observed for other transition metal complexes with porphyrins [83-85].

First, the decolorization reaction was performed in air irradiating a stirred aqueous solution of RhB by visible light (Figure S7 and Figure 15). We anticipated that due to the high light absorptivity the complex and emissive properties can be useful for generation of reactive oxygen species (ROS) as free-base porphyrins and metalloporphyrins such as $\mathrm{Cu}$ (II) and $\mathrm{Zn}$ (II) complexes. The reaction was monitored by UV-vis spectroscopy with time interval of 5 min. The decrease of absorption band intensity was used as a criterion of degradation efficiency and the analysis was performed using changes of absorbance band maximum $(555 \mathrm{~nm})$. The degradation yield $(R \%)$ was calculated by using the relationship: $R(\%)=\left(\frac{C_{o}-C_{t}}{C_{o}}\right) \cdot 100$, where $C_{t}$ and $C_{\mathrm{o}}$ are the concentrations at time $t$ and initial concentration, respectively.

The oxidation of RhB didn't occurs without adding Cr(III) complexes. After addition of the complexes, the reactions proceeded with similar rates and the studied solutions lost their color near completely (95-97\%) after $30 \mathrm{~min}$ of the irradiation (Figure 15). Thus, $\mathrm{Cr}(\mathrm{III})$ complexes accelerate the $\mathrm{RhB}$ decolorization by air but the nature of axial ligands does not affect the reaction course.

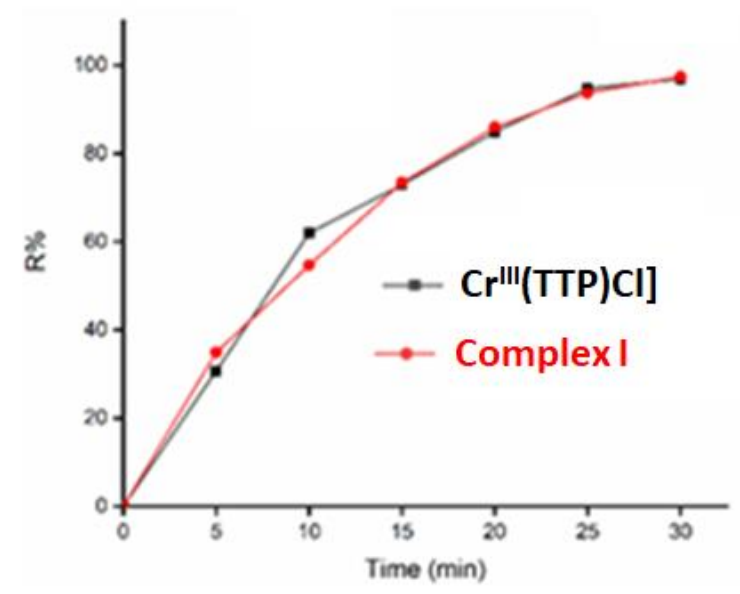


Figure 15. Variation of the degradation efficiency of the Rhodamine B dye upon the irradiation by white LED ( $20 \mathrm{~W}$ ) time using $\left[\mathrm{Cr}^{\text {III }}(\mathrm{TTP}) \mathrm{Cl}\right]$ and complex $\mathbf{I}$ as catalysts.

Next, we investigated the decolorization of $\mathrm{RhB}$ by hydrogen peroxide since this compound is one of the most promising sustainable oxidants for developing chemical processes in industry [86]. After addition of the complex and hydrogen peroxide to the aqueous solution of $\mathrm{RhB}$, the reaction mixture was stirred at room temperature (Figure S8 and Figure 16) and monitored by UV-vis spectroscopy as discussed above. It is noteworthy that the initial reaction rate was higher in the presence of complex $\mathbf{I}$. However, then the reaction is slowed down and after $30 \mathrm{~min}$ of the reaction the degree of the $\mathrm{RhB}$ decomposition was comparable in both experiments (77 and $72 \%$, for $\mathrm{Cr}$ (III) porphyrins bearing chloride and cyanate ligands, respectively). It is also worth to note that the RhB decolorization by hydrogen peroxide was not observed without adding of the $\mathrm{Cr}(\mathrm{III})$ complexes.

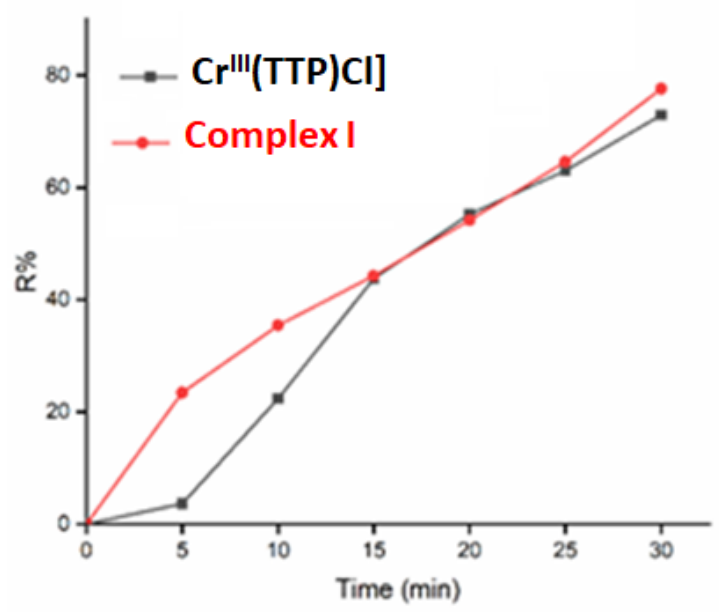

Figure 16. Decolorization efficiency $(R \%)$ curves of the Rhodamine $\mathrm{B}$ dye as a function of time for $\left[\mathrm{Cr}^{\mathrm{III}}(\mathrm{TTP})(\mathrm{Cl}]\right.$ and complex $\mathbf{I}$.

The difference in the influence of the axial ligands on the initial reaction rates of the photooxidation and this reaction probably indicates that different oxidant species are involved in these oxidation 
reactions. Additional experiments are needed to clarify their mechanisms before to assume how the axial ligands influence on the reaction courses.

\section{Conclusion}

In summary, the reaction of (chlorido)[meso-(tetratolyl)porphyrinato]chromium(III) $\left(\left[\mathrm{Cr}^{\mathrm{III}}(\mathrm{TTP}) \mathrm{Cl}\right]\right)$ with an excess of KOCN and cryptand-222 in dichloromethane solution leads to the hexacoordinated bis $($ cyanato- $\kappa N) \mathrm{Cr}(\mathrm{III})$ complex with the formula $\left[\mathrm{K}(\right.$ crypt-222) $]\left[\mathrm{Cr}^{\mathrm{III}}(\mathrm{TTP})(\mathrm{NCO})_{2}\right] \cdot 2 \mathrm{H}_{2} \mathrm{O}($ complex I). This species was characterized by ESI-HRMS mass spectrometry, IR, UV-vis and fluorescence spectroscopies, cyclic voltammetry and single crystal X-ray analysis. This complex crystalizes in the non-asymmetric $C 222_{1}$ space group and the chromium center is octahedrally coordinated by the four nitrogen atoms of the porphyrin macrocycle occupying the equatorial plane and by two nitrogen atoms of the cyanate- $\kappa N$ ligand in the axial sites. This is a rare example of metalloporphyrin in which two negatively charged cyanate ligands are axially coordinated to the metal center. The crystal lattice of complex $\mathbf{I}$ is sustained by several weak intermolecular hydrogen bonds while $\pi$ - $\pi$ stacking of porphyrin ring does not observe. The Hirshfeld surface analysis indicates that the most significant contacts in packing are $\mathrm{H} . . . \mathrm{H}(61.4 \%)$, followed by $\mathrm{C} \ldots \mathrm{H}(21.3 \%)$ and $\mathrm{H} . . . \mathrm{O}(13.6 \%)$. Our preliminary studies of catalytic properties of newly synthesized complex demonstrated that it has a potential in oxidation reactions which are among most difficult to perform in the production of fine chemicals. The compound was efficient as a catalyst in the decomposition of Rhodamine B dye by hydrogen peroxide. Moreover, this complex was used as photocatalyst of photodecomposition of this dye by oxygen probably due to its high light absorptivity and efficiency in generation of reactive oxygen species (singlet oxygen and superoxide anion).

\section{Declaration of Competing Interest}

The authors declare that they have no known competing financial interests or personal relationships that could have appeared to influence the work reported in this paper.

\section{Supplementary materials}


Supplementary material associated with this article can be found, in the online version, at doi:XxxxXXXXXXXXXXXXXX.

[1] H. Kobayashi, Y. Kaizu, Photodynamics and electronic structures of metal complexes, Coord. Chem. Rev. 64 (1985) 53-64, doi: 10.1016/0010-8545(85)80041-2.

[2] K. Okada, A. Sumida, R. Inagaki, M. Inamo, Effect of the axial halogen ligand on the substitution reactions of chromium(III) porphyrin complex, Inorg. Chim. Acta 392 (2012) 473-477. doi: 10.1016/j.ica.2012.04.00.

[3] E. B. Fleischer, T. S. Srivastava, Some chromium and molybdenum tetraphenylporphines, Inorg. Chim. Acta 5 (1971) 151-154, doi: 10.1016/S0020-1693(00)95901-2.

[4] E. B. Fleischer, M. Krishnamurthy, Kinetics of the substitution reactions of a Cr(III)-porphyrin, J. Coord. Chem. 2 (1972) 89-100, doi: 10.1080/00958977208072957.

[5] G. N. La Mar, F. A. Walker, Proton Nuclear Magnetic Resonance Line Widths and Spin Relaxation in Paramagnetic Metalloporphyrins of Chromium(III), Manganese(III), and Iron(III), J. Am. Chem. Soc. 95, (1973) 6950-6956, doi: 10.1021/ja00802a014.

[6] D. A. Summerville, R. D. Jones, B. M. Hoffmann, F. Basolo, Chromium(III) Porphyrins. Chemical and Spectroscopic Properties of Chloro-meso-tetraphenylporphinatochromium(III) in Nonaqueous Solutions J. Am. Chem. Soc. 99 (1977) 8195-8202, doi: 10.1021/ja00467a012.

[7] E. M. Davoras, R. Diaper, A. Dervissi, M. J. Tornaritis, A. G. Coutsolelos, Comparative ${ }^{1}$ H NMR and UV-visible studies of polyene polymer epoxidations catalyzed by iron(III), manganese(III) and chromium(III) porphyrins, J Porphyr. Phthalocyanines, 2 (1998) 53-60, doi : 10.1002/(SICI)1099-1409(199801/02)2:1<53::AID-JPP51>3.0.CO;2-M

[8] O. M. Chukanov, G. P. Belov, Reaction between carbon dioxide and propylene oxide catalyzed by cobalt and chromium porphyrin complexes: The effect of reaction conditions on the reaction rate, Kinet. Catal. 58 (2017) 397-401, doi: 10.1134/S0023158417040048.

[9] N. D. Boscher, D. Duday, P. Heier, K. Heinze, F. Hilt, P. Choquet, Atmospheric pressure plasma polymerisation of metalloporphyrins containing mesoporous membranes for gas sensing applications, Surf. Coat. Technol., 234 (2013) 48-52, doi: 10.1016/j.surfcoat.2012.12.034.

[10] M. Guergueb, J. Brahmi, S. Nasri, F. Loiseau, K. Aouadi, V. Guerineau, S. Najmudin, H. Nasri, Zinc(II) triazole meso-arylsubstituted porphyrins for UV-visible chloride and bromide detection. 
Adsorption and catalytic degradation of malachite green dye, RSC Adv. 10 (2020), 22712-22725, doi: 10.1039/d0ra03070h.

[11] M. Guergueb, S. Nasri, J. Brahmi, F. Loiseau, F. Molton, T. Roisnel, V. Guerineau, I. TurowskaTyrkf, K. Aouadi, H. Nasri, Effect of the coordination of $\pi$-acceptor 4-cyanopyridine ligand on the structural and electronic properties of meso-tetra(para-methoxy) and meso-tetra(para-chlorophenyl) porphyrin cobalt(II) coordination compounds. Application in the catalytic degradation of methylene blue dye, RSC Adv. 10 (2020) 10 6900-6918, doi: 10.1039/c9ra08504a.

[12] S. Nasri, M. Hajji, M., Guergueb S. Dhifaoui, V. Marvaud, F. Loiseau, F. Molton, T. Roisnel, T. Guerfel, H. Nasri, Spectroscopic, Electrochemical, Magnetic and Structural Characterization of an Hexamethylenetetramine Co(II) Porphyrin Complex - Application in the Catalytic Degradation of Vat Yellow 1 dye, J. Mol. Struct. 1231 (2021), 129676, doi : org/10.1016/j.molstruc.2020.129676.

[13] R. Soury, M. Jabli, T. A. Saleh, W. S. Abdul-Hassan, E. Saint-Aman, F. Loiseau, C. Philouze, H. Nasri, Tetrakis(ethyl-4(4-butyryl)oxyphenyl)porphyrinato zinc complexes with 4,4-bpyridin: synthesis, characterization, and its catalytic degradation of Calmagite, RSC Adv. 8 (2018) 2014320156, doi: 10.1039/c8ra01134f.

[14] S. K. Das, P. Ghosh, I. Ghosh, A. K. Guha, Adsorption of rhodamine B on Rhizopus oryzae: role of functional groups and cell wall components, Colloids Surf. B 65 (2008) 30-34, DOI: 10.1016/j.colsurfb.2008.02.020.

[15] P. Botek, J. Poustka, J. Hajslova, Determination of Banned Dyes in Spices by Liquid Chromatography-Mass Spectrometry, Czech J. Food Sci. 25 (2007) 17-24, doi: 10.17221/737-CJFS

[16] B. S. Inbaraj, J. T. Chien, G. H. Ho, J. Yang, B. H. Chen, Equilibrium and kinetic studies on sorption of basic dyes by a natural biopolymer poly( $\gamma$-glutamic acid), Biochem. Eng. J. 31 (2006) 204215, doi: 10.1016/j.bej.2006.08.001.

[17] T. Shimada, H. Yamazaki, M. Mimura, Y. Inui, F.P. Guengerich, Interindividual variations in human liver cytochrome P-450 enzymes involved in the oxidation of drugs, carcinogens and toxic chemicals: studies with liver microsomes of 30 Japanese and 30 Caucasians, J. Pharmacol. Exp. Ther. 270 (1994) 414-423, https://pubmed.ncbi.nlm.nih.gov/8035341/

[18] R. L. Hill, M. Gouterman, A. Ulman, Tetraphenylporphyrin Molecules Containing Heteroatoms Other Than Nitrogen. 7.1. Emission and Electronic Structure of Rings Containing Sulfur and Selenium, Inorg. Chem. 21 (1982) 1450-1455, https://doi.org/10.1021/ic00134a037.

[19] E. J. Shin, D. Kim, Substituent effect on the fluorescence quenching of various tetraphenylporphyrins by ruthenium tris(2,2'-bipyridine) complex, J. Photochem. Photobiol. A 152 (2002) 25-31. https://doi.org/10.1016/S1010-6030(02)00189-2. 
[20] F.L. Hirshfeld, Bonded-atom fragments for describing molecular charge densi- ties, Theoret. Chim. Acta. 44 (1977) 129-138, doi: 10.10 07/BF0 0549096.

[21] S. K. Wolff, D. J. Grimwood, J. J. McKinnon, D. Jayatilaka, M. A. Spackman, Crystal Explorer, Version 1.5, University of Western Australia, Perth, Australia (2007).

[22] S. K. Wolff, D. J. Grimwood, J. J. McKinnon, M. J. Turner, D. Jayatilaka, M.A. Spack-man, CrystalExplorer 3.1 (2013), University of Western Australia, Crawley, Western Australia, (n.d.). http://hirshfeldsurface.net/CrystalExplorer.

[23] M. A. Spackman, J. J. McKinnon, Fingerprinting intermolecular interactions in molecular crystals, CrystEngComm 4 (2002) 378-392, doi: 10.1039/B203191B.

[24] M. A. Spackman, D. Jayatilaka, Hirshfeld surface analysis, CrystEngComm 11 (2009) 19-32, doi: 10.1039/B818330A.

[25] GaussView, Guassian, Inc. (Carnergie Office Parck-Building6 Pittsburgh PA 151064 USA), Copyright (C) 2000-2003 Semichem. Inc.

[26] Gaussian 09, Revision C.01, Frisch, M.J.; Trucks, G.W.; Schlegel, H.B.; Scuseria, G.E.;

Robb, M.A.; Cheeseman, J.R.; Scalmani, G.; Barone, V.; Mennucci, B.; Petersson, G.A.; Nakatsuji, H.; Caricato, M.; Li, X.; Hratchian, H.P.; Izmaylov, A.F.; Bloino, J.; Zheng, G.; Sonnenberg, J.L.; Hada, M.; Ehara, M.; Toyota, K.; Fukuda, R.; Hasegawa, J.; Ishida, M.; Nakajima, T.; Honda, Y.; Kitao, O.; Nakai, H.; Vreven, T.; Montgomery, J.A., Jr.; Peralta, J.E.; Ogliaro, F.; Bearpark, M.; Heyd, J.J.; Brothers, E.; Kudin, K.N.; Staroverov, V.N.; Kobayashi, R.; Normand, J.; Raghavachari, K.; Rendell, A.; Burant, J.C.; Iyengar, S.S.; Tomasi, J.; Cossi, M.; Rega, N.; Millam, N.J.; Klene, M.; Knox, J.E.; Cross, J.B.; Bakken, V.; Adamo, C.; Jaramillo, J.; Gomperts, R.; Stratmann, R.E.; Yazyev, O.; Austin, A. J.; Cammi, R.; Pomelli, C.; Ochterski, J. W.; Martin, R.L.; Morokuma, K.; Zakrzewski, V.G.; Voth, G.A. Salvador, P.; Dannenberg, J.J.; Dapprich, S.; Daniels, A.D.; Farkas, Ö.; Foresman, J.B.; Ortiz, J.V. Cioslowski, J.; Fox, D.J. Gaussian, Inc., Wallingford CT (2009).

[27] C. Lee, W. Yang, R. G. Parr, Development of the Colle-Salvetti correlation-energy formula into a functional of the electron density, Phys. Rev. B 37 (1988) 785-789.

https://doi.org/10.1103/PhysRevB.37.785.

[28] A. D. Becke, Becke's three parameter hybrid method using the LYP correlation functional, J. Chem. Phys. 98 (1993) 5648-5652, https://doi.org/10.1063/1.464913. 
[29] C. Liu, D. Zhang, M. Gao, S. Liu, DFT studies on second-order nonlinear optical properties of a series of axially substituted bis(salicylaldiminato) zinc(II) Schiff-base complexes, Chem. Res. Chin. Univ. 31 (2015) 597-602, https://doi.org/10.1007/s40242-015-5004-7.

[30] N. Zhanpelsov, M. Matsuoka, H. Yamashite, M. Anpo, Cluster Quantum Chemical ab Initio Study on the Interaction of NO Molecules with Highly Dispersed Titanium Oxides Incorporated into Silicalite and Zeolites, J. Phys. Chem. B 102 (1998) 6915-6920, https://doi.org/10.1021/jp981402k.

[31] N. Niclasc, M. Dolg, H. Stoll, H. Preuss, Ab initio energy-adjusted pseudopotentials for the noble gases Ne through Xe: Calculation of atomic dipole and quadrupole polarizabilities, J. Chem. Phys. 102 (1995) 8942-8952, https://doi.org/10.1063/1.468948.

[32] A. D. Adler, F. R. Longo, J. D. Finarelli, J. Goldmacher, J. Assour and L. Korsakoff, A simplified synthesis for mesotetraphenylporphine, J. Org. Chem. 32, (1967) 476-476, https://doi.org/10.1021/jo01288a053.

[33] D. A. Summerville, R. D. Jones, B. M. Hoffman, F. Basolo, Chromium(III) porphyrins. Chemical and spectroscopic properties of chloro-meso-tetraphenylporphinatochromium(III) in nonaqueous solutions, J. Am. Chem. Soc. 99 (1977) 8195- 8202, https://doi.org/10.1021/ja00467a012.

[34] SMART, SAINT, and SADABS, Bruker AXS Inc., (2008), Madison, WI, USA.

[35] A. Altomare, G. Cascarano, C. Giacovazzo, A. Guagliardi, M.C. Burla, G. Polidori, M. Camalli, SIRPOW.92 - A program for automatic solution of crystal structures by direct methods optimized for powder data, Journal of Applied Crystallography 27 (1994) 435-436, doi: 10.1107/S0 0218898940 0 0221.

[36] G.M. Sheldrick, Crystal structure refinement with SHELXL, Acta Cryst C 71 (2015) 3-8, doi: 10.1107/S2053229614024218.

[37] P. McArdle, SORTX - A program for on-screen stick-model editing and autosort- ing of SHELX files for use on a PC, J. Appl. Crystallogr. 28 (1995) 65, doi: 10.1107/S0021889894010642.

[38] A.L. Spek, PLATON SQUEEZE: a tool for the calculation of the disordered sol- vent contribution to the calculated structure factors, Acta Crystallogr C Struct Chem 71 (2015) 9-18, doi: 10.1107/S2053229614024929.

[39] C. F. Macrae, I. J. Bruno, J. A. Chisholm, P. R. Edgington, P. McCabe, E. Pidcock, L. Rodriguez-Monge, R. Taylor, J. van de Streek, P.A. Wood, Mercury CSD 2.0 - New features for the visualization and investigation of crystal structures, J Appl Cryst 41 (2008) 466-470, 
doi: $10.1107 / \mathrm{S} 0021889807067908$.

[40] K. S. Suslick, R. A. Watson, The photochemistry of chromium, manganese, and iron porphyrin complexes, New. J. Chem. 16 (1992) 633-642,

[41] Gouterman M., The Porphyrins, Dolphin D., Ed., Vol. III, p. 1, Academic, N. Y., 1978.

[42] Hanson L. K., Eaton W. A., Sligar S. G., Gunsalus I. C., Gouterman M., Connell C. R., Origin of the anomalous Soret spectra of carboxycytochrome P-450, J. Am. Chem. Soc. 98 (1976) 2612-2674, https://doi.org/10.1021/ja00425a050.

[43] H. Kobayashi, Y. Yanagawa, H. Osada, S. Minami, M. Shimizu, Electronic Spectra of High-Spin Iron(III) Tetraphenylporphins, Bull. Chem. Sot. Jpn, 46 (1973) 1471-147, https://doi.org/10.1246/bcsj.46.1471.

[44] M. Gouterman, K. H. Hanson, G. E. Khalil, W. R. Leenstra, J. W. Bouchler, Porphyrins. XXXII. Absorptions and luminescence of $\mathrm{Cr}(\mathrm{III})$ complexes, J. Phys. Chem. 62 (1975) 2343-2353, http://dx.doi.org/10.1063/1.430760.

[45] T. Ozawa, A. Hanaki, Axial ligation of nitrogenous bases to five-coordinate chloro-mesotetraphenylporphyrinatochromium(III), Inorg. Chim. Acta 102 (1985) 169-171, https://doi.org/10.1016/S0020-1693(00)86755-9.

[46] S. V. Zaitseva, S. A. Zdanovich, and O. A. Golubchikov, Chromium(III) and Chromium(IV) Tetraphenylporphine Complexes, Russ. J. Coord. Chem. 28 (2002) 843-847, https://doi.org/10.1023/A:1021630228084.

[47] C. A. Reed, J. K., Kouba, C. J. Grimes, S. K. Cheung, Manganese(II) and Chromium(II) Porphyrin Complexes: Synthesis and Characterization, Inorg. Chem. 17 (1978) 2666-2670, https://doi.org/10.1021/ic50187a057.

[48] H. Nasri, M. K. Ellison, M. Shang, C. E. Schulz, W. R. Scheidt, Variable $\pi$-Bonding in Iron(II) Porphyrinates with Nitrite, $\mathrm{CO}$, and tert-Butyl Isocyanide: Characterization of [Fe(TpivPP)(NO $\left.\left(\mathrm{NO}_{2}\right)(\mathrm{CO})\right]^{-}$, Inorg. Chem. 43 (2004) 2932-2942, https://doi.org/10.1021/ic035119y.

[49] K. Colladet, M. Nicolas, L. Goris, L. Lutsen, D. Vanderzande, Low-band gap polymers for photovoltaic applications, Thin Solid Films 451 (2004) 7-11, https://doi.org/10.1016/j.tsf.2003.10.085. 
[50] J. R. Darwent, P. Douglas, A. Harriman, G. Porter and M.-C. Richoux, Metal phthalocyanines and porphyrins as photosensitizers for reduction of water to hydrogen, Coord. Chem. Rev. 44 (1982) 83126, https://dx.doi.org/10.1016/S0010-8545(00)80518-4.

[51] J. W. Owens, R. Smith, R. Robinson, M. Robins, Photophysical properties of porphyrins, phthalocyanines, and benzochlorins, Inorg. Chim. Acta 279 (1998) 226-231, https://doi.org/10.1016/S0020-1693(98)00137-6.

[52] S. Nasri, I. Zahou, I. Turowska-Tyrk, T. Roisnel, F. Loiseau, E. Saint-Amant, H. Nasri, Synthesis, Electronic Spectroscopy, Cyclic Voltammetry, Photophysics, Electrical Properties and X-ray Molecular Structures of meso-\{Tetrakis[4-(benzoyloxy)phenyl]porphyrinato $\}$ zinc(II) Complexes with Aza Ligands Eur. J. Inorg. Chem. (2016) 5004-5019, https://doi.org/10.1002/ejic.201600575.

[53] N. Amiri, S. Nouir, M. Hajji, T. Roisnel, T. Guerfel, G. Simonneaux and H. Nasri, Synthesis, structure, photophysical properties and biological activity of a cobalt(II) coordination complex with 4,4bipyridine and porphyrin chelating ligands, J. Saudi Chem. Soc. 23 (2019) 781-794, https://doi.org/10.1016/j.jscs.2019.03.003.

[54] D. J. Darensbourg, A. I. Moncada, Mechanistic Insight into the Initiation Step of the Coupling Reaction of Oxetane or Epoxides and $\mathrm{CO}_{2}$ Catalyzed by (salen)CrX Complexes, Inorg. Chem.47 (2008) 10000-10008, https://doi.org/10.1021/ic801231p.

[55] M. A. Bush, G. A. Sim, Metal-carbonyl and metal-nitrosyl complexes. Part VIII. Molecular structure of isocyanatocyclopentadienyldinitrosylchromium, J. Chem. Soc. A (1970) 605-611, https://doi.org/10.1039/J19700000605.

[56] W. R. Scheidt, C. A. Reed, Stereochemistry of the toluene solvate of .alpha. ,.beta.,.gamma.,. delta.-tetraphenylporphinatochromium(II), Inorg.Chem. 17 (1978) 710-714, https://doi.org/10.1021/ic50181a042.

[57] W. R. Scheidt, A. C. Brinegar, J. F. Kirner, C .A. Reed, Stereochemistry of low-spin bis(pyridine)(meso-tetraphenylporphinato)chromium(II), Inorg. Chem. 18 (1979) 3610-3612, https://doi.org/10.1021/ic50202a066.

[58] M. Inamo, K. Nakajima, Effect of a Sterically Hindered Imidazole Ligand on the Molecular Structure and Axial Ligand Substitution Reaction of the Chromium(III) Porphyrin Complex Bull. Chem. Soc. Jpn. 71 (1998), 71, 883-891, https://doi.org/10.1246/bcsj.71.877.

[59] H. Shuo, S. Gu, Y. Liu, R. Jin, H. Yingyong, Chin. J. Appl. Chem. 8 (1991), 8, 67. 
[60] K. Oyaizu, A. Haryono, Y. Nishimura, K. Yamamoto, E. Tsuchida, Molecular Structure of a $\mu-$ Oxo Chromium-Iron Complex: Rare Example of a Crystallographically Characterized $\mu$-Oxo Heterometallic Porphyrin, Bull. Chem. Soc. Jpn. 72 (1999) 1781-1784, https://doi.org/10.1246/bcsj.72.1781.

[61] A. L. Balch, L. Latos-Grazynski, B. C. Noll, M. M. Olmstead, E. P. Zovinka, Geometric and electronic structure of paramagnetic tetraarylporphyrin complexes of chromium, Inorg. Chem. 13 (1992) 1148-1151, https://doi.org/10.1021/ic00033a007.

[62] M. Inamo, H. Nakaba, K. Nakajima, M. Hoshino, Laser Photolysis of Chromium(III) Porphyrins with Axial Pyridines in Dichloromethane and Toluene Solutions. Novel Effects of a Hydrogen Bond in the Ligand Exchange Reaction, Inorg. Chem. 39 (2000) 4417-4423, https://doi.org/10.1021/ic0002059.

[63] J. T. Groves, W. J. Kruper Junior, R. C. Haushalter, W. M. Butler, Synthesis, characterization, and molecular structure of oxo(porphyrinato)chromium(IV) complexes, Inorg. Chem. 21 (1982) 13631368, https://doi.org/10.1021/ic00134a018.

[64] J. T. Groves, T. Takahashi, W. M. Butler, Synthesis and molecular structure of a nitrido(porphyrinato)chromium(V) complex, Inorg. Chem. 22 (1983) 884-887, https://doi.org/10.1021/ic00148a009.

[65] K. Ezzayani, Z. Denden, S. Najmudin, C. Bonifácio, E. Saint-Aman, F. Loiseau, H. Nasri, Exploring the Effects of Axial Pseudohalide Ligands on the Photophysical and Cyclic Voltammetry Properties and Molecular Structures of MgII Tetraphenyl/porphyrin Complexes, Eur. J. Inorg. Chem. (2014) 5348-5361, https://doi.org/10.1002/ejic.201402546.

[66] Z. Denden, K. Ezzayani, E. Saint-Aman, F. Loiseau, S. Najmudin, C. Bonifácio, J-C. Daran, H. Nasri, Insights on the UV/Vis, Fluorescence, and Cyclic Voltammetry Properties and the Molecular Structures of Zn(II) Tetraphenylporphyrin Complexes with Pseudohalide Axial Azido, Cyanato-N, Thiocyanato-N, and Cyanido Ligands, Eur. J. Inorg. Chem. (2015) 2596-2610, doi:10.1002/ejic.201403214.

[67] B. Belhaj Ali, M. S. Belkhiria, J.-C. Daran, H. Nasri, (2.2.2-Cryptand)potassium bis-(cyanato$\kappa \mathrm{N})(5,10,15,20$-tetra-phenyl-por-phy-rin-ato- $\kappa(4) \mathrm{N})$ cobaltate(III) chloro-benzene hemisolvate. Acta Crystallogr., Sect.E:Struct. Rep.Online 68 (2012) m1262-m1263, https://doi.org/10.1107/s1600536812038317. 
[68] P. Turner, M. J. Gunter, B. W. Skelton, A. H. White, Crystal Structures of the Pentacoordinate Bromo, Isocyanato, Iodo, Acetato and Isothiocyanato Complexes of the mesoTetraphenylporphyrinatomanganese Cation, Aust. J. Chem. 51 (1998) 835-852, https://doi.org/10.1071/C97150.

[69] M. Dhifet, M. S. Belkhiria, J. -C .Daran, C. E. Schulz, H. Nasri, Synthesis, spectroscopic and structural characterization of the high-spin Fe(II) cyanato-N and thiocyanato-N "picket fence" porphyrin complexes, Inorg. Chim. Acta (2010), 363, 3208-3213, doi:10.1016/j.ica.2010.05.058.

[70] S. Goswami , B. K. Tripuramallu, S. Ganguly. Structural perception into the supramolecular selfassembly directed by $\mathrm{C}-\mathrm{H} \bullet \bullet \pi$ and $\pi \bullet \bullet \pi$ interactions of 5,15-Di(40 -carboxyphenyl)-10,20-Di(pyrenyl) zinc porphyrin linker, J. Mol. Struct. 1227 (2020) 129567, https://doi.org/10.1016/j.molstruc.2020.129567.

[71] S. Adhikaria, T. Bhattacharjeeb, P. Nathc, A. Dasd, J. P. Jasinskie, R. J. Butcherf, D. Maitic, Bimetallic and trimetallic $\mathrm{Cd}(\mathrm{II})$ and $\mathrm{Hg}$ (II) mixed-ligand complexes with 1,1-dicyanoethylene-2,2dithiolate and polyamines: Synthesis, crystal structure, Hirshfeld surface analysis, and antimicrobial study, Inorg. Chim. Acta 512 (2020) 119877, https://doi.org/10.1016/j.ica.2020.119877.

[72] J. H. Furhop, K. M. Kadish, D. G. Davis, Redox behavior of metallo oxtaethylporhyrins, J. Am. Chem. Soc. 95, 1973, 5140-5147, https://doi.org/10.1021/ja00797a008.

[73] Stephen K. Cheung, Carol J. Grimes, Janice Wong, and Christopher A. Reed, Chromium(II) porphyrins and an irreversible dioxygen complex, J. Am, Chem. Soc, 98 (1976) 5028-3030, https://doi.org/10.1021/ja00432a061.

[74] Fred, Basolo, Robert, D. Jones, David, A. Summerville, Equilibrium Constants for the Axial Coordination of meso-Tetraphenylporphinatomanganese(II) and -chromium(III) Complexes. Acta Chem. Scand. A., 32 (1978), 771-780, doi: 10.3891/acta.chem.scand.32a-0771.

[75] L. A. Bottomley, K. M. Kadish, Solvent and ligation effects on the electroreduction of chromium porphyrins, Inorg. Chem.22 (1983) 342-349, https://doi.org/10.1021/ic00144a028.

[76] S. L. Kelly, K. M. Kadish, Electron-transfer and ligand-addition reactions of (TPP)CrClO4 and (TPP)Cr(NO) in nonaqueous media, Inorg. Chem. 23 (1984) 679-687, https://doi.org/10.1021/ic00174a010.

[77] Y. Murakami, Y. Matsuda, S. Yamada, Transition-metal complexes of pyrrole pigments. Part 20. Redox behaviour of chromium complexes with macrocyclic tetrapyrroles, J. Chem. Soc., Dalton Trans. 23 (1981) 679-687, https://doi.org/10.1021/ic00174a010. 
[78] M. Inamo, M. Hoshino, K. Nakajima, S. Aizawa, S. Funahashi, Reactivity of Five-Coordinate Intermediate Generated by Laser Photolysis of Monoligated Chloro(5,10,15,20tetraphenylporphinato)chromium(III) in Toluene, Bull. Chem. Soc. Jpn., 68 (1995) 2293-2303, https://doi.org/10.1246/bcsj.68.2293

[79] N. Okulik, A. H. Jubert, Theoretical Analysis of the Reactive Sites of Non-steroidal Antiinflammatory Drugs, Internet Electronic Internet Electron. J. Mol. Des. 4 (2005) 17-30, http://www.biochempress.com.

[80] J. C. Barona-Castaño, C. C. Carmona-Vargas, T. J. Brocksom, K. T. De Oliveira, Porphyrins as Catalysts in Scalable Organic Reactions, Molecules, 21 (2016) 310. https://doi.org/10.3390/molecules21030310.

[81] M. M. Pereira, L. D. Dias, M. J. F. Calvete, Metalloporphyrins: Bioinspired Oxidation Catalysts, ACS Catalysis, 8 (2018) 10784-10808. https://doi.org/10.1021/acscatal.8b01871.

[82] A. Kechich, R. Soury, M. Jabli, K.M. Alenezi, C. Philouze, H. Nasri, Synthesis of novel bis(cyano) meso-tetraphenylporphyrinato-chromium(III), [K(222)][Cr $\left.{ }^{\mathrm{III}}(\mathrm{TPP})(\mathrm{CN})_{2}\right] 2 .\left(\mathrm{C}_{7} \mathrm{H}_{6} \mathrm{O}_{2}\right)(\mathrm{III})$, and (Chloro) meso-tetraphenylporphyrinato-chromium(III), [Cr ${ }^{\mathrm{III}}$ (TPP)Cl] (II): Spectroscopic, physico-chemical, and decolorization properties, Inorg. Chem. Commun.,128 (2021) 108588. https://doi.org/https://doi.org/10.1016/j.inoche.2021.108588.

[83] M. F. Powell, E. F. Pai, T. C. Bruice, Study of (tetraphenylporphinato)manganese(III)-catalyzed epoxidation and demethylation using p-cyano-N,N-dimethylaniline $\mathrm{N}$-oxide as oxygen donor in a homogeneous system. Kinetics, radiochemical ligation studies, and reaction mechanism for a model of cytochrome P-450, J. Am. Chem. Soc., 106 (1984) 3277-3285. https://doi.org/10.1021/ja00323a036.

[84] G. R. Karimipour, M. Montazerozohoori, B. Karami, Efficient Biomimetic Decarboxylation of Diphenylacetic Acid by [Mn(TPP)X]n-Bu $\mathrm{NIO}_{4}$ Catalytic Systems: Effect of Anionic Axial Ligands (X-), J. Chem. Res., 2006 (2006) 605-608. https://doi.org/10.3184/030823406778521428.

[85] L. A. Bottomley, F. L. Neely, Stereoelectronic Aspects of Inter-Metal Nitrogen Atom Transfer Reactions between Nitridomanganese(V) and Chromium(III) Porphyrins, Inorg. Chem., 36 (1997) 5435-5439. https://doi.org/10.1021/ic960919c.

[86] W. F. Hoelderich, F. Kollmer, Oxidation reactions in the synthesis of fine and intermediate chemicals using environmentally benign oxidants and the right reactor system, Pure Appl. Chem., 72 (2000) 1273-1287. https://doi.org/10.1351/pac200072071273. 
